\title{
Sacred Cars? Cost-Effective Regulation of Stationary and Non-stationary Pollution Sources
}

\author{
Meredith Fowlie, Christopher R. Knittel and Catherine Wolfram*
}

July 2009

\begin{abstract}
For political and practical reasons, environmental regulations sometimes treat point source polluters, such as power plants, differently from mobile source polluters, such as vehicles. This paper measures the extent of this regulatory asymmetry in the case of nitrogen oxides (NOx), the criteria air pollutant that has proven to be the most recalcitrant in the United States. We find significant differences in marginal abatement costs across source types with the marginal cost of reducing NOx from cars less than half of the marginal cost of reducing NOx from power plants. Our findings have important implications for the efficiency of NOx emissions reductions and, more broadly, the benefits from increasing the sectoral scope of environmental regulation. We estimate that the costs of achieving the desired emissions reductions could have been reduced by nearly $\$ 2$ billion, or 9 percent of program costs, had marginal abatement costs been equated across source types.
\end{abstract}

${ }^{*}$ We would like to thank Tim Brennan, Leigh Linden, Erin Mansur and seminar participants at Columbia University, Ohio State University, University of Alberta, UC Davis, UC San Diego, UC Santa Barbara and the National Bureau of Economic Research for valuable comments. Justin Gallagher, Rob Seamans and Orie Shelef provided excellent research assistance. Fowlie: Department of Agriculture and Resource Economics, University of California, Berkeley and NBER. Email: mfowlie@are.berkeley.edu. Knittel: Department of Economics, University of California, Davis; University of California Energy Institute and NBER. Email: crknittel@ucdavis.edu. Wolfram: Haas School of Business, University of California, Berkeley; University of California Energy Institute and NBER. Email: wolfram@haas.berkeley.edu. 


\section{Introduction}

A basic tenet in microeconomics holds that, if production has been efficiently allocated, marginal costs should be equalized across producers. Past empirical work has demonstrated that this equivalence does not always hold in practice. For instance, in the presence of market power (Borenstein, Bushnell and Wolak, 2002), trade restrictions (Pavcnik, 2002) or industry regulation (Olley and Pakes, 1996), failure to equate marginal costs across producers has resulted in substantial efficiency losses.

In the context of environmental regulation, the same principle should apply. The "goods" produced are improvements in environmental quality. In the specific case of emissions regulation, the "producers" are pollution sources capable of reducing their emissions. The equivalence of marginal emissions abatement costs across sources is a necessary condition for cost-effective emissions reduction, provided that marginal damages do not vary significantly across sources. The extent to which this efficiency condition will be satisfied depends significantly on how policymakers design and implement environmental regulations.

Many pollutants are emitted by multiple sources in multiple sectors of the economy. For instance, any high temperature combustion process emits nitrogen oxides (NOx), so planes, trains, boats, trucks, tractors, cars, and stationary sources such as power plants are all sources, although they are currently all subject to different NOx emissions standards in the U.S. ${ }^{1}$ In general, the health and environmental damages caused by a specific amount of a given pollutant at a given location at a given point in time are the same regardless of its source. Cost-effective regulation of NOx emissions should therefore equate the marginal cost of abatement across similarly located sources.

For decades, economists have emphasized the efficiency gains associated with market-based environmental policies. Indeed, the large-scale shift away from the more traditional, more prescriptive "command-and-control" approaches for regulating stationary point sources of pollution (such as technology standards) towards market-based approaches (such as cap-and-trade programs) has largely been justified on these grounds. A similar transition to market-based policy instruments has not occurred for mobile sources such as passenger vehicles. While there has been considerable attention paid to analyzing how much more efficiently market-based programs coordinate pollution abatement across point sources subject to the same environmental regulatory program, ${ }^{2}$ far less

\footnotetext{
${ }^{1}$ Nitrogen oxides (NOx) are binary compounds composed of oxygen and nitrogen. The most important forms of $\mathrm{NOx}$ in the atmosphere are nitrogen monoxide $(\mathrm{NO})$ and nitrogen dioxide $\left(\mathrm{NO}_{2}\right)$.

${ }^{2}$ Detailed analyses of the efficiency of the Acid Rain Program include Stavins (1998), Keohane (2005) and Shadbegian et al. (2006). Fowlie (2008) looks at the NOx Budget Program.
} 
work has been done to evaluate how efficiently abatement activity is coordinated across regulatory programs and sectors. This paper aims to fill that gap.

We analyze regulations designed to reduce NOx emissions from point and mobile sources, respectively. Nitrogen oxides, a byproduct of fossil fuel combustion, are precursors to the formation of fine particulate matter and ground-level ozone. ${ }^{3}$ Exposure to elevated concentrations of either pollutant has been linked to significant human health and ecosystem damages (see, for example, Brunekreef and Holgate, 2002; WHO, 2003). We measure the difference between the marginal cost of abating NOx emissions from power plants and the marginal cost of abating NOx emissions from passenger vehicles and calculate the resulting inefficiencies. Our estimates suggest that the efficiency gains from symmetric regulatory treatment across sectors are most likely larger (in dollar terms) than past estimates of gains from switching from command and control to market-based approaches. So, while there are large gains from replacing command-and-control policies with more market-based approaches, debates about the sectoral scope of a program may be equally important. These results are particularly relevant to the increasing public discourse about mechanisms for regulating greenhouse gas emissions, which are emitted by many sectors of the economy. ${ }^{4}$

There are several reasons why we might observe differential regulatory treatment of different pollution sources in practice. First, if damages caused per unit of pollution vary significantly across mobile and point sources, differential regulatory treatment of source types is warranted. Section 7 of the paper summarizes the findings of an increasingly sophisticated literature that investigates how NOx emissions impact the production, transport, and deposition of harmful pollutants such as particulate matter and ground-level ozone. Although the available evidence is far from conclusive, the current state of the science does not support the hypothesis that damages caused per unit of NOx emissions vary significantly across mobile versus point sources.

Second, positive political economy theories of regulation such as Stigler (1971) suggest that regulations that impose costs on a small, well organized and politically powerful interest group and for which the benefits are diffuse are less likely to be adopted than regulations for which the costs are diffuse and the benefits concentrated. Stringent environmental regulation may be less likely to apply to politically powerful firms who vehemently oppose the regulation. In the United States, the automobile manufacturing industry is more concentrated than wholesale electricity generation. Perhaps more importantly, domestic vehicle manufacturers are more likely to see their

\footnotetext{
${ }^{3}$ Oxygen and nitrogen gases in air will not react at ambient temperatures. However, in an internal combustion engine, temperatures get high enough to drive the reactions between atmospheric nitrogen and oxygen in the flame that yield NOx.

${ }^{4}$ The costs of U.S. policies to reduce greenhouse gas emissions may be at least as high as the costs of all other environmental policies combined (Aldy and Pizer, 2008), so steps to minimizes costs will yield large efficiency gains.
} 
profits negatively impacted by stringent environmental regulations, whereas electricity producers operating in economically regulated industry environments can expect to recover environmental compliance costs in the form of higher prices.

From a practical or political transaction costs perspective, the costs associated with implementing regulations may vary. For instance, boats and airplanes are governed by international laws, so in order for the U.S. to implement NOx standards for these, they would need to coordinate with other countries. By contrast, power plants and passenger vehicles fall squarely within the jurisdiction of state and federal environmental regulators.

We aim to measure the extent to which current U.S. environmental policy deviates from the theoretical optimum by comparing the marginal costs of abating NOx emissions from power plants to the marginal cost of abating NOx emissions from passenger vehicles. Specifically, we compare the cost of reducing NOx under the Federal Tier 2 passenger vehicle emissions reduction program to the cost of reducing NOx at power plants subject to the NOx Budget Program. Both programs were promulgated in 2004, pursuant to the 1990 Clean Air Act Amendments (CAAA). Both programs represent incremental steps taken to increase the stringency of the NOx regulations for mobile and industrial point sources, respectively.

We construct estimates of NOx marginal abatement costs for power plants using detailed unitlevel engineering data and compare them to estimates for light duty car and truck NOx abatement costs based on engineering analyses performed for the regulatory impact analysis of Tier 2. Our estimates of the marginal abatement costs for point sources are more than double those of mobile sources.

A core strength of this paper is that the engineering data allow us to calculate not only the marginal cost of pollution abatement that corresponds with the level of NOx reductions mandated by the existing regulations we observe, but also the costs of abatement options that provide too little or too much reduction (i.e. were infra- or extra-marginal). Put differently, because we estimate marginal abatement cost curves (versus individual points along these curves) we are able to estimate the efficiency losses from the current policy approach to regulating NOx emissions.

We find there is considerable scope for efficiency gains. Our preferred estimates of marginal abatement costs suggest that inefficiencies amount to $\$ 1.7$ billion, or nine percent of the total costs incurred to comply with both programs. To put these findings in perspective, the gains from coordinating abatement costs within the critically acclaimed Acid Rain Program are estimated to be $\$ 94$ million, or 17 percent of total compliance costs (Shadbegian et al., 2006). Although the cost inefficiencies we estimate are somewhat lower in percentage terms, the efficiency gains in dollar 
terms are significantly higher. Our results highlight the importance of increasing the sectoral-scope of cap-and-trade programs. Although there are several examples of well-functioning, multi-sector emissions trading programs (including the European Union Emissions Trading Program), broadbased market designs often meet with considerable resistance. For example, the current framework for California's GHG cap-and-trade program separates transportation from the other GHG emitting sectors of the economy.

The rest of the paper proceeds as follows. Section 2 describes the NOx Budget Program and the Tier 2 vehicle emissions reduction programs. Section 3 describes generically how we will use estimates of the marginal abatement cost curves to measure efficiency losses. In Section 4, we elaborate on the advantages of using engineering estimates in this application. Section 5 presents the main results of the paper. We first explain how we construct the marginal abatement cost curves for both power plants and for vehicles, and then presents our results. Section 6 discusses ancillary information we have collected to buttress the engineering cost estimates we use to construct the marginal abatement curves. As the results in Section 5 assume that the marginal damages of NOx emissions do not vary by source or geographic location, Section 7 discusses the existing evidence on this assumption, which generally seems to support it. Section 8 discusses several additional programs aimed at reducing NOx, and Section 9 concludes.

\section{Regulating Nitrogen Oxide Emissions}

Nitrogen oxides $(\mathrm{NOx})$ contain nitrogen and oxygen in varying amounts. NOx form when fuels are burned at high temperatures. In 2002, just before the programs we study were implemented, motorized passenger vehicles and electricity generation were responsible for nearly 18 percent and 23 percent, respectively, of man-made NOx emissions. Additional NOx emitters include other motorized vehicles and industrial sources (see Figure 1).

NOx is the only criteria pollutant for which nationwide emissions have actually increased since the passage of the 1970 Clean Air Act. ${ }^{5}$ NOx emissions cause environmental and health damages through a number of channels. First, NOx reacts with volatile organic compounds (VOCs) in the presence of sunlight to form tropospheric ozone. Exposure to elevated ambient ozone concentrations has been linked to increased hospitalization for respiratory ailments, irreversible reductions in lung

\footnotetext{
${ }^{5}$ Criteria air pollutants are the only air pollutants for which the Administrator of the U.S. Environmental Protection Agency has established national air quality standards defining allowable ambient air concentrations. Congress has focused regulatory attention on these pollutants (i.e. carbon monoxide, lead, nitrogen dioxide, ozone, particulate matter, and sulfur dioxide) because they endanger public health and they are widespread throughout the U.S.
} 
capacity, and ecological damages (Grypares, 2004; WHO, 2003). ${ }^{6}$ Second, NOx emissions can react with other compounds in the atmosphere to form nitrate particulate matter (PM). Studies have found that exposure to fine particulates is correlated with increased infant mortality (Chay and Greenstone, 2003) and with increased adult mortality from respiratory or cardiopulmonary disease (Lippman and Schlessinger, 2000). NOx emissions also contribute to a range of other health and environmental problems, including acid deposition and nutrient loading in waterways.

\subsection{Reducing NOx emissions from point sources}

The 1990 CAAA placed unprecedented emphasis on reducing NOx emissions and bringing urban areas into compliance with federal ozone standards. The Amendments established thoroughly revised NOx emissions standards for existing point sources in non-attainment areas and all new sources. ${ }^{7}$ Because it was anticipated that these measures would be insufficient to bring the northeastern region of the United States into attainment with federal ozone standards, the Amendments also established the Ozone Transport Commission (OTC) to assess the degree of ozone transport in the northeast and to recommend strategies to mitigate regional ozone problems.

Using detailed models of ozone formation and transport, the OTC demonstrated the regional nature of the ozone transport problem and identified the need for significant reductions in NOx emissions across the eastern U.S. (OTAG, 1997; U.S. EPA, 1997). The NOx Budget Program, officially upheld by the U.S. Court of Appeals in 2000, was designed to facilitate cost effective reductions of NOx emissions from large stationary sources in 19 eastern states.

The NOx Budget Program (NBP) caps NOx emissions from large point sources in the Eastern United States. The vast majority of these emissions come from coal-fired electricity generators. Tradable NOx emissions permits are allocated (for free) to facilities in the program. Because ozone is only a problem during the warm summer months, the NBP is only in effect during "ozone season" (i.e., May through September). To remain in compliance with the program, affected point sources must hold permits equal to their ozone season NOx emissions. All facilities were required to comply beginning in May 2004.

\footnotetext{
${ }^{6}$ The impacts of ozone on mortality have been difficult to establish, possibly because it is difficult to separate deaths from ozone exposure from deaths associated with heat.

${ }^{7}$ Prior to the 1990 Amendments, existing sources of NOx faced little, if any, binding regulation.
} 


\subsection{Reducing NOx emissions from mobile sources}

For mobile sources, the 1990 CAAA introduced new "Tier 1" standards (measured in grams of NOx per mile) that tightened pre-existing standards by 40 percent and 50 percent for cars and light trucks, respectively. The Amendments further required that the EPA continue to assess the merits, cost-effectiveness, and feasibility of tighter emission standards for the 2004 model year and beyond. The National Low Emission Vehicle program (NLEV), which was passed in 1998 and adopted nationwide in 2001, further reduced NOx emissions by 50 percent and 19 percent for cars and light trucks, respectively.

In December 1999, the U.S. EPA signed the "Tier 2" standard which further increased the stringency of exhaust emission standards for new passenger cars and light-duty vehicles. ${ }^{8}$ The Tier 2 NOx emissions standard of 0.07 grams per mile (gpm) represented a 77 percent reduction for cars and a 65-95 percent reduction for trucks. These standards were phased in beginning in 2004 .

\section{Measuring Efficiency from Regulatory Coordination}

If the value of the health and environmental benefits associated with reducing NOx emissions at point sources is equal, per ton of emissions reductions, to the value of reducing vehicular NOx emissions, economic efficiency would dictate that marginal abatement costs should be set equal across the two sectors. Section 7 summarizes the scientific evidence documenting the relative impacts of mobile and point source NOx emissions. Although this evidence is not conclusive, it is generally consistent with the conclusion that there is no significant difference in the social benefits from incremental emissions reductions achieved by sources regulated under the two programs we consider. Thus, we assume that these values do not differ significantly in our initial analysis. Sensitivity analysis summarized in section 7 explores the implications of relaxing that assumption.

Let $p$ and $m$ denote point and mobile sources, respectively. Let the level of emissions reductions required by regulations of source type $s \in\{p, m\}$ be $\bar{R}_{s}$. The function $M A C_{s}\left(R_{s}\right)$ specifies the marginal cost of abating NOx emissions among sources of type $s$ by $R_{s}$. Figure 2 illustrates a case where $M A C_{x}\left(\bar{R}_{x}\right)<M A C_{y}\left(\bar{R}_{y}\right), x \neq y$. The difference between area $\mathrm{B}$ and area $\mathrm{A}$ reflects the economic inefficiency resulting from a lack of regulatory program coordination. This efficiency loss $L$ is equal to:

\footnotetext{
${ }^{8}$ The program also established a new maximum sulfur level in gasoline.
} 


$$
L=\int_{\bar{R}_{y}-\Delta R}^{\bar{R}_{y}} M A C_{y}(q) d q-\int_{\bar{R}_{x}}^{\bar{R}_{s}+\Delta R} M A C_{x}(q) d q,
$$

where $\Delta R$ is defined such that:

$$
M A C_{x}\left(\bar{R}_{x}+\Delta R\right)=M A C_{y}\left(\bar{R}_{y}-\Delta R\right)
$$

To measure $L$, we first construct estimates of the functions $M A C_{p}\left(R_{p}\right)$ and $M A C_{m}\left(R_{m}\right)$. We then identify the levels of emissions reductions $\bar{R}_{p}$ and $\bar{R}_{m}$ that correspond to the constraints imposed by the NBP and Tier 2 standards, respectively. Upon finding that $M A C_{p}\left(\bar{R}_{p}\right)>$ $M A C_{m}\left(\bar{R}_{m}\right)$, we define $x=m$ and $y=p$ and estimate (1).

When estimating (1), we are taking the total level of mandated NOx reductions as given. Put differently, we are implicitly assuming that the mandated level of emissions reduction is either the socially optimal or the maximum politically achievable level of reductions. An evaluation of the efficiency of observed levels of regulatory stringency would require estimating both marginal abatement cost curves and marginal damage curves. Estimating the damages associated with different levels of NOx concentrations is both complex and controversial (Muller and Mendelsohn, 2008). Consequently, we do not take on this calculation.

\section{Engineering versus Econometric Evidence}

Our research design relies on engineering models and related data that were available ex ante, as opposed to ex post observed outcomes. It is useful to consider the advantages and disadvantages of using engineering estimates as compared to the more traditional approach in the economics literature which involves constructing econometric estimates of the parameters of an underlying cost function using data collected ex post. Although the econometric approach has its advantages, we argue that engineering cost estimates are more appropriate for our purposes. ${ }^{9}$

Our objective is to assess the efficacy of regulatory coordination. To execute our analysis, we need to estimate abatement cost curves for both the electricity and automotive sectors. This requires estimating both the costs of technologies that were adopted and the costs of available abatement options that were not implemented. One approach to constructing these curves could

\footnotetext{
${ }^{9}$ This is by no means the first paper to make use of engineering estimates in a detailed economic analysis. Recent papers utilizing engineering estimates of costs to benchmark electricity sector performance include Wolfram (1999), Borenstein, Bushnell and Wolak (2002) and Joskow and Kahn (2002).
} 
have involved estimating an econometric model using data describing the observed compliance decisions that coal plant operators and automotive manufacturers actually made. The problem with this approach is that estimates are likely to be biased. Plant operators presumably install the abatement technologies that are best suited for their plant, given both observable and unobservable (to the econometrician) factors. Using ex post observed data to impute the costs of abatement options that were not chosen would require very strong assumptions regarding the conditional independence of observed costs and unobserved determinants of the compliance decision.

An alternative approach makes use of engineering estimates. Prior to the implementation of the NBP and Tier 2 programs, detailed analyses and field testing of available pollution control technologies had been carried out by industry trade groups, emissions control equipment manufacturers, and other stakeholders. Highly disaggregated estimates of installation costs, variable operating costs, and performance parameters across boiler or vehicle type were well documented. It is these rich data on expected costs that we use in our analysis. These estimates fail to capture unanticipated changes in costs, optimization errors, or behavioral responses and idiosyncrasies that caused decision-makers to deviate from the engineering ideal. ${ }^{10}$ However, omission of these potentially significant factors is appropriate in an analysis of whether these two NOx regulations were coordinated cost effectively given the information available to policymakers.

\section{Results}

\subsection{Constructing a marginal abatement cost curve for power plants}

We estimate NOx abatement costs for 632 coal-fired generating units in the NBP. Although gasand oil-fired generators and other industrial point sources are also included in the NBP, these 632 coal-fired units represent over 90 percent of the NOx emissions regulated under the program. ${ }^{11}$ The U.S. EPA reports that coal-fired electricity generators account for almost all (over 98 percent) of the NOx emissions reductions achieved under the NBP (U.S. EPA, 2005).

Coal plant managers had a variety of NOx control technologies to choose from when they were deciding how to comply with the NBP. The capital costs, variable operating costs and emissions reduction efficiencies associated with different pollution control technologies vary significantly, both

\footnotetext{
${ }^{10}$ Fowlie (2008) provides one example of such a deviation in the context of NOx pollution abatement technology, as she shows that firms under traditional regulation were more likely to invest in capital-intensive abatement technology compared to firms operating in deregulated electricity markets.

${ }^{11}$ Our analysis focuses exclusively on coal-fired plants due to data availability constraints. The unit-level cost data required to carry out this analysis are not available for gas- and oil-fired generators.
} 
across NOx technology types and across generating units with different technical characteristics. Also, not all control technologies are compatible with all boiler types. In total, fifteen different compliance strategies are observed in the data. These strategies are: combustion modification, combustion modification combined with low NOx burners, four different types of low NOx burner technologies, low NOx burners combined with SCR, overfire air, overfire air combined with low NOx burners, SCR, SNCR, SCR with overfire air, SNCR with overfire air, low NOx burners, SCR and overfire air, and no retrofits. ${ }^{12}$

In the foregoing analysis, we will assume that reductions in NOx emissions are achieved through pollution control technology retrofits and combustion modifications. We do not consider plant retirement or reduced unit utilization rates as compliance options. This assumption finds empirical support. ${ }^{13}$

We generate unit-specific engineering estimates of technology installation and operating costs using detailed unit- and plant-level data. In the late 1990s, to help generators prepare to comply with market-based NOx regulations, the Electric Power Research Institute (EPRI) ${ }^{14}$ developed a software program to generate cost estimates for all major NOx control options, conditional on unit- and plant-level characteristics. ${ }^{15}$ Cost calculations require detailed data on over 60 unit- and plant-level operating characteristics, fuel inputs, boiler specifications, plant operating costs, etc. Appendix A includes a detailed description of the data. Post-retrofit emissions rates are estimated using the EPRI software, together with EPA's Integrated Planning Model (U.S. EPA 2003).

We use the EPRI software to first identify which NOx control technologies are compatible with each boiler, and then to generate cost estimates for each unit, for each viable control technology. Let $j=1 \ldots J_{n}$ index the NOx control technology options available to the $n t h$ electricity generating unit. Let $K_{n j}$ represent the engineering cost estimates of required capital investments specific to unit $n$ and technology $j ; v_{n j}$ is the corresponding variable operating cost estimate (per $\mathrm{kWh}$ ) and $e_{n j}$ represents the corresponding post-retrofit emissions rate. Let $e_{n 0}$ represent the pre-retrofit

\footnotetext{
${ }^{12}$ Compliance options that incorporate Selective Catalytic Reduction (SCR) technology can reduce emissions by up to ninety percent. NOx emissions rates can be reduced by thirty-five percent through the adoption of Selective Non-Catalytic Reduction Technology (SNCR). Pre-combustion control technologies such as low NOx burners (LNB) or combustion modifications (CM) can reduce emissions by fifteen to fifty percent, depending on a boiler's technical specifications and operating characteristics.

${ }^{13}$ EPA modeling exercises predicted that less than 0.3 percent of capacity would be prematurely retired as a result of this program (US EPA, 1998). To date, no program-related retirements have been reported. Because coal-fired generation tends to serve load on an around-the-clock basis, the utilization rates of these coal plants have not been significantly affected by this regulation (Fowlie, 2008).

${ }^{14} \mathrm{EPRI}$ is an organization that was created and is funded by public and private electric utilities to conduct electricity related $R \& D$.

${ }^{15}$ Anecdotal evidence suggests that this software has been used not only by plant managers, but also by regulators to evaluate proposed compliance costs for the utilities they regulate (Himes, Musatti, Srivastra).
} 
emissions rate; this is the amount of $\mathrm{NOx}$ the $n t h$ unit emits per $\mathrm{kWh}$ of electricity generated if it installs no new pollution controls. For each unit, for each compliance option, we calculate the net present value (NPV) of estimated pollution control costs $c_{n j}$ and emissions reductions $R_{n j}$ as follows:

$$
\begin{aligned}
c_{n j} & =K_{n j}+\sum_{t=1}^{T_{n}} \frac{v_{n j} Q_{n}}{(1+r)^{t}}, \\
R_{n j} & =\sum_{t=1}^{T_{n}} \frac{\left(e_{n o}-e_{n j}\right) Q_{n}}{(1+r)^{t}} .
\end{aligned}
$$

We assume that generating units are retired at 65 years, so $T_{n}$ is set equal to 65 minus the $n t h$ unit's age in 2000. ${ }^{16}$ Historic electricity production during the ozone season, $Q_{n}$, is used to proxy for expected ozone season production. To facilitate cost comparisons across point-source and mobile-source emissions reduction cost estimates, we set $r=0.07 .^{17}$

The second and third columns of Table 1 present engineering estimates of the NPV costs $c$ and NPV emissions reductions $R$ associated with the technology options available to a $510 \mathrm{MW}$ unit in our data set with $T_{n}=31$. These options are listed in order of increasing $R_{j}$. This particular unit, which is representative of other units in the dataset, has nine compliance options. At one extreme, if the firm relies entirely on the permit market for compliance, $c_{0}=R_{0}=0$. At the other extreme, the firm makes a large capital investment in pollution control equipment and reduces emissions by over 19,000 tons.

A simple, static model is used to represent the compliance decisions made by plant managers in the NBP. Simplifying assumptions implicit in this model are discussed in detail below. We assume that the manager of unit $n$ chooses the compliance option that minimizes the NPV of anticipated compliance costs:

$$
\min _{j}\left\{c_{n j}+\tau \sum_{t=1}^{T_{n}} \frac{e_{n j} Q_{n}}{(1+r)^{t}}\right\}, j \in\left\{0, \ldots, J_{n}\right\},
$$

where the second argument in parentheses reflects the cost of permits which the units must hold to offset any uncontrolled emissions and $j=0$ identifies the option that involves a complete reliance on the permit market for compliance. Let $j_{n}^{*}$ identify the investment choice of the $n t h$ firm:

\footnotetext{
${ }^{16}$ Note that we are not attributing any cost to NOx reductions from the new plants replacing these units once they retire. This is consistent with the assumption that if new plants comply with new source standards, the cap will cease to bind as new plants make up a larger share of the fleet.

${ }^{17}$ The U.S. EPA uses a discount rate of seven percent in their analysis of the Tier 2 standard.
} 
$j_{n}^{*} \in\left\{0 \ldots J_{n}\right\}$. The pollution permit price $\tau$ and the vector of investment decisions $\mathbf{j}^{*}=\left(j_{1}^{*}, \ldots, j_{N}^{*}\right)$ describe the equilibrium for the permit market if for each $n=1 \ldots N, j_{n}^{*}$ solves [2] subject to the constraint that $\sum_{n=1}^{N} e_{n j_{n}^{*}} \cdot Q_{n} \leq \bar{E} \cdot{ }^{18}$

The model assumes that all plant managers commit to a compliance strategy at the beginning of the program. This rules out any option value; plants will not wait for more information about market conditions before committing to costly investments in pollution control equipment. This is an appropriate assumption within our analytical framework because there is no uncertainty about future abatement costs; the entire abatement cost curve is explicitly represented and plants are assumed to choose the cost minimizing compliance option. Uncertainty about future input costs was unlikely to strongly favor waiting as the control technologies had similar inputs.

In fact, modeling plant-level compliance decisions as one-shot decisions made at the outset of the program is consistent with the compliance decisions that were actually made. In preparation for compliance, there was unprecedented investment in pollution control equipment. NOx controls installed by power producers in the years leading up to the program were sufficient to reduce emissions by as much as a third below the required levels (Natural Gas Week, 2004).

The model further assumes that plant managers expected permit price to remain constant over time (in real terms) when they made their compliance decision. This is an oversimplification, but not an unreasonable first order approximation. Permits of future vintages were trading actively during the period that firms were making their compliance decisions. If futures permit prices are plotted (in nominal terms) against vintage (or maturity), trends are decreasing at a decreasing rate. A discount rate of 10 percent best fits the data.

Figure 3 plots the average cost $\frac{c_{n j}}{R_{n j}}$ as a function of $R_{n j}$ for the representative unit summarized in Table 1. Note that several of the available compliance options will not be cost minimizing at any permit price. For example, with an average cost of $\$ 0.50 /$ lb reduced, option 2 will never be chosen because option 3, which delivers greater emissions reductions, is associated with a lower average cost of $\$ 0.36 /$ lb. Assuming compliance cost minimizing behavior, options $1,2,4$, and 5 will never be chosen by this unit.

Let $J_{n}^{\prime}$ represent the subset of $J_{n}: \forall j_{n}^{\prime} \in J_{n}^{\prime}$ there exists a permit price $\tau$ such that $j_{n}^{\prime}$ is the compliance cost minimizing choice. Any compliance choice that is not included in $J_{n}^{\prime}$ will not be chosen by a compliance cost minimizing plant manager. In the example depicted in Figure 3, $J^{\prime}=\{0,3,6,7,8\}$. These compliance options appear in bold face in Table 1 .

\footnotetext{
${ }^{18}$ This assumes intertemporal arbitrage in the permit market, competitive permit and product markets, certainty about future abatement costs, and no intertemporal restrictions on permit banking and borrowing.
} 
We calculate unit- and choice-specific marginal abatement costs $m a c_{n j^{\prime}}$ for all $n$, for all $j_{n}^{\prime} \in J_{n}^{\prime}$, where marginal abatement costs are defined as:

$$
m a c_{n j^{\prime}}=\frac{c_{n j^{\prime}+1}-c_{n j^{\prime}}}{R_{n j^{\prime}+1}-R_{n j^{\prime}}}
$$

The numerator represents the additional costs incurred from choosing the next cleanest option in $J_{n}^{\prime}$. The denominator represents the additional emissions reductions achieved. Note that the compliance cost minimizing choice for the $n t h$ unit is $j_{n}^{\prime}$ if $m a c_{n j^{\prime}}<\tau<m a c_{n j^{\prime}+1}$. The final column of Table 1 reports marginal abatement costs for the relevant compliance alternatives available to this particular unit.

Our aggregate marginal abatement cost curve reflects the horizontal summation of the unitspecific marginal abatement cost curves. Specifically, we construct an aggregate marginal abatement cost curve by using a model of the NBP pollution permit market mechanism that coordinates the unit-level environmental compliance decisions. We simulate pollution permit market clearing for a range of possible values of $\bar{E}$. We begin by setting the cap equal to uncontrolled emissions $\bar{E}_{0}=\sum_{n=1}^{632} e_{n 0} \cdot Q_{n}$. In this benchmark case, the equilibrium permit price is $\tau=\$ 0$ and $j^{*}=j_{0} \forall n$. The cap is then incrementally decreased to $\bar{E}_{1}=\bar{E}_{0}-\varepsilon$. A permit price of $\$ 0$ offers no incentive to invest in pollution control equipment. A strictly positive permit price is required to deliver a level of aggregate emissions that satisfies the new constraint $\sum_{n=1}^{N} e_{n j_{n}^{*}} \cdot Q_{n} \leq \bar{E}_{1}$. The permit price is then incrementally increased until the vector of equilibrium choices $\mathbf{j}^{*}$ with a corresponding vector of equilibrium emissions $\mathbf{e}_{n j^{*}}$ satisfies the constraint imposed by $\bar{E}_{1}$. This entire process is repeated $R$ times. At each iteration, we make the cap incrementally more stringent and solve for the constrained equilibrium price. The resulting $\left\{\bar{E}_{r}, \tau_{r}\right\}$ pairs can be used to trace out a marginal abatement cost curve for this group of facilities.

Figure 4 plots aggregate abatement $\left(\bar{E}_{0}-\bar{E}_{r}\right)$ versus equilibrium permit price $\tau_{r}$ for $R=2000$ and $\varepsilon=1$. For each level of $\bar{E}$, the corresponding permit price represents the minimum $\tau$ required to induce sufficient abatement among this group of point sources such that aggregate emissions equal $\bar{E}$. The vertical line corresponds to the cap imposed by the NBP. $R_{p}^{*}$ is set equal to the discounted emissions reductions associated with the technology adoption decisions that these units actually made. ${ }^{19}$ The equilibrium permit price $\tau\left(R_{p}^{*}\right)$ that corresponds to these choices (and the

\footnotetext{
${ }^{19}$ Information about which compliance strategies were chosen by coal plant managers was obtained from the Environmental Protection Agency, the Energy Information Administration, the Institute for Clean Air Companies and M.J. Bradley and Associates. These choices imply discounted NOx emissions reductions of 6.7 million tons. An
} 
corresponding emissions reductions) is $\$ 1920$ per ton. ${ }^{20}$

\subsection{Constructing a marginal abatement cost curve for mobile sources}

To construct the marginal abatement cost curve for passenger vehicles, we rely on the Tier 2 Regulatory Impact Analysis performed by the EPA (U.S. EPA, 1999a). ${ }^{21}$ As part of the regulatory process, the EPA forecast total NOx savings and the costs associated with these savings; we discuss each of these in this section.

The costs associated with compliance can be split into increases in vehicles costs, fixed costs associated with engineering, and fixed costs associated with certification. While we refer the reader to the EPA's analysis for all of the particulars, we highlight the important assumptions regarding consumer purchasing behavior and vehicle-level cost of compliance.

As with point sources, there are a variety of ways auto manufacturers can alter vehicles to comply with the new legislation. The least cost method for complying is likely to vary by both a vehicle's size and type of engine. To account for this, the EPA calculates estimates of the least cost method of compliance separately for each vehicle class/number of cylinder combination. ${ }^{22}$ The per vehicle cost estimates are reported in Table $2 .^{23}$

After calculating the incremental engineering costs for each vehicle type, the EPA makes two assumptions in the process of transforming the variable costs to marginal abatement costs. First, the incremental costs are increased by 26 percent to account for "overhead and profits." Below we present results that use the EPA's assumed markup and results that assume a markup of zero. We take the estimates without the markups as the most accurate estimate of the marginal cost of abatement, as any markup represents a transfer, rather than a true economic costs. The relevant cost for efficiency calculations is the marginal social cost of abatement, not the marginal cost of

alternative approach to defining the "observed" cap would involve computing the discounted sum of the mandated annual emissions caps going forward. This is complicated by the fact that the regulation only defines caps for the first few years of the program.

${ }^{20}$ We compare our estimates to realized permit prices in section 6.1.

${ }^{21}$ Executive Order 12866 requires the US Environmental Protection Agency to provide the Office of Management and Budget with detailed Regulatory Impact Analyses (RIAs) for all new "economically significant" regulatory proposals. A proposal is deemed to be economically significant if annual costs are expected to exceed $\$ 100 \mathrm{M}$. Both Tier 2 and the NBP fall into this category.

${ }^{22}$ There are a number of changes that can be made to autos to reduce NOx; changes to the catalytic converter system are likely to be most important. Other areas that manufacturers can alter include: improvements to the fuel injection system, secondary air injection, insulating the exhaust system, engine combustion chamber improvements and exhaust gas recirculation.

${ }^{23}$ The NBP calculations are in $\$ 2000$ s, while the Tier 2 calculations are in $\$ 1997 \mathrm{~s}$. However, according to the BLS PPI calculations, there was no change in the PPI over the intervening years. 
abatement faced by consumers. Note that if consumers face a higher vehicle price because of higher markups, there will be some welfare loss to the extent there are fewer vehicles sold. In our context, this amounts to the markup over a cost that is already small relative to the overall vehicle price, so we assume that those welfare losses are trivial.

The EPA also assumes that manufacturers experience learning over the course of Tier 2, beginning in the third year of implementation. Specifically, they assume that each time output doubles a manufacturer experiences a 20 percent reduction in incremental vehicle costs. If their assumed learning rate is either too large or too small, this assumption will tend to under- or overstate the marginal cost of abatement for mobile sources.

In addition to vehicle equipment costs, the EPA estimates quasi-fixed costs associated with Tier 2. These costs include $\mathrm{R} \& \mathrm{D}$, tooling and certification costs. $\mathrm{R} \& \mathrm{D}$ costs are assumed to be $\$ 5$ million per vehicle line (100,000 vehicles), tooling costs are assumed to be $\$ 2$ million per vehicle line and certification costs are assumed to be $\$ 15$ million industry wide. ${ }^{24}$ When calculating the discounted value of costs, the EPA assumes that fixed costs are spread evenly over the first five years. The effects of learning and fixed costs can be seen by examining vehicles costs over time. Table 3 reports vehicle costs, by vehicle type, in years one, three and six. Costs from year one to year three fall by between $\$ 5$ and $\$ 34$ because of learning. Costs fall significantly in year six because fixed costs expire.

Combined, the assumptions on variable and fixed costs, markups and learning yield vehicle costs that vary by vehicle type/engine type and year. Table 3 reports the sales weighted average of these costs by vehicle type and year. A final requirement needed to generate estimates of the total discounted costs associated with Tier 2 is a model of consumer vehicle purchase behavior. For this, the EPA relies on a model of driving and purchasing behavior known as MOBILE5. ${ }^{25}$ The vehicle cost and sales data imply total annual costs beginning at $\$ 269$ million, when Tier 2 is being phased in, and peaking at $\$ 1579$ million in 2009 ; annual costs begin to fall after 2009 because of learning.

The EPA uses the cost estimates associated with Tier 2 to calculate an average cost of the proposed NOx reductions; this requires an estimate of the total NOx saved under Tier 2. The amount of NOx saved under Tier 2 will depend on both driving habits and the stock of vehicles in each year. Driving habits come from the MOBILE6 model, while the EPA uses NHTSA survivor

\footnotetext{
${ }^{24}$ The EPA has attempted to estimate these costs as incremental fixed costs; that is, those additional fixed costs associated with Tier 2. In each case, however, they suggest that they have erred on the side of overstating these costs.

${ }^{25}$ The cost estimates also require an assumption about the phase in of the standards. The EPA assumes that manufacturers meet the requirements by starting with the smaller vehicles and moving to the larger vehicles. If anything, this will overstate the cost of achieving a given emissions level, as it is not necessarily the cost-minimizing approach.
} 
rates for each vehicle. This generates annual emissions for the assumed stock of vehicles, which is then summed using a seven percent discount rate. ${ }^{26}$ Under these assumptions and the standard EPA assumption when dealing with mobile sources that treats NOx and non-methane hydrocarbons as the same, the EPA forecasts a lifetime discounted reductions for NOx+NMHC to be 23.5 million tons. Table 4 reports savings throughout the lifetime of the program; savings increase over time as more and more Tier 2 vehicles are on the road.

Calculating the marginal abatement cost for the regulatory program is complicated by the fact that Tier 2 also yields reductions in other pollutants, most notably sulfur and particulate matter. There are three potential ways to deal with this. One, and probably least accurate, is to simply ignore them; we refer to this strategy as the "uncredited MAC." A second is to assign a value for these other pollutant reductions and reduce the costs associated with Tier 2 by this amount; this is strategy taken by the EPA and we refer to this strategy as the "credited MAC." To do this, the EPA forecasts the amount of each pollutant saved and credits the costs associated with Tier 2 ; they assume marginal damages of $\$ 4,800 /$ ton and $\$ 10,000 /$ ton for sulfur and particulate matter, respectively. ${ }^{27}$

The structure of Tier 2 allows for a third strategy. Given that Tier 2 consisted of two distinct regulatory changes, desulfurization of fuels and changes in vehicle emissions equipment, we can calculate the abatement costs assuming that the EPA only implemented the vehicle portion of the regulations. We refer to this strategy as the "separated MAC."

Calculating the level of abatement absent desulfurization requires calculating (a) the amount of the Tier 2 NOx reductions coming from non-Tier 2 vehicles burning desulfurized fuel and (b) the increase in NOx emissions from Tier 2 vehicles that would occur if these vehicles ran on the existing fuels. Both require estimates of how emissions change with the sulfur content of the fuel; the former also requires information on the driving and retirement patterns for non-Tier 2 vehicles. We use information in the RIA and the MOBILE6 model to estimate the emissions reductions that would have occurred absent desulfurization.

The RIA provides estimates of the NOx savings associated with shifting non-Tier 2 vehicles to desulfurized fuel. Given these estimates, we use the EPA's MOBILE6 model of driving patterns and retirements of existing vehicles to calculate the increase in emissions from assuming the savings from

\footnotetext{
${ }^{26}$ Because Tier 2 does not apply to California, Alaska and Hawaii, the EPA adjusts their numbers to represent emission levels for the remaining 47 states.

${ }^{27}$ Recent work by Muller and Mendelsohn (2007) suggests EPA assumptions about marginal damages from PM and sulfur could be high. Muller and Mendelsohn estimate average marginal damages per ton per year of $\mathrm{PM}_{2.5}$ ranging from $\$ 3,300$ to $\$ 500$ in urban and rural areas, respectively. Average marginal damages from $\mathrm{SO}_{2}$ are estimated to be $\$ 1,500$ and $\$ 900$ per ton per year in large cities and rural areas, respectively.
} 
existing vehicles is zero. These calculations imply that 12.7 percent of the NOx savings associated with Tier 2 are the result of non-Tier 2 automobiles running on desulfurized fuel. Given the estimate of the savings from the existing vehicle stock, we calculate how the remaining 87.3 percent would be affected. We again use the EPA's estimates of how NOx emissions change with the sulfur content of fuels; we then apply these to Tier 2 vehicles. The EPA estimates that desulfurization of the fuels reduces NOx emissions from Tier 2 vehicles by 25.2 percent. Combined these suggest that the NOx savings under a policy that only altered vehicles emission controls would have been 65.3 percent absent desulfurization. ${ }^{28}$

Once the level of abatement is known for our three estimation strategies, we require information on costs. The RIA explicitly reports both credited and uncredited average cost of NOx abatement, as well as separating the costs for the vehicle emissions equipment and desulfurization portions of the regulation. We use this information and additional information in the RIA to subtract out the assumed markup to generate a total cost for each of the three methods of accounting for sulfur and PM. Specifically, Table V-53 of the RIA reports the annualized costs separately for the NOx and sulfur portions of the legislation for the years 2004 to 2024; Table V-51 reports annual costs for desulfurization for 2004 to 2030. The text of the RIA also reports that the discounted value of total costs associated with the entire legislation are $\$ 48.5$ billion. ${ }^{29}$ Using these data, we are able to change the assumption about markups. Table 5 reports the average costs for each of our methods. Evident from this is that the method for controlling for sulfur and particulate matter is very important. Ignoring the reductions in both sulfur and particulate matter implies a marginal abatement cost of $\$ 2040 /$ ton. Using the EPA's values for the sulfur and particulate matter reduces this cost to $\$ 1320 /$ ton; ${ }^{30}$ subtracting out the assumed markup reduces this further to $\$ 1164 /$ lbs.

Treating the vehicle and fuel regulations separately yields much lower average cost estimates. Allowing for the assumed margin, the average cost is $\$ 1108 /$ ton. Removing the margin reduces this to $\$ 896 /$ ton. These results imply that the burden placed on refiners was much larger than the burden placed on automobile manufacturers. This is consistent with the political economy story

\footnotetext{
${ }^{28}$ The EPA relies on a variety of assumptions to estimate the NOx reductions from Tier 2. These include: the phase-in of Tier 2 vehicles, the efficacy of emission systems on existing vehicle stock, driving habits and how sulfur affects catalytic converters. In general, our estimates are robust to the assumptions that only affect existing vehicles because the NOx savings from existing vehicles are low.

The main parameter of interest for Tier 2 vehicles is how sulfur affects catalytic converter operation; for the parameter the EPA does not provide much insight regarding the range of possibilities. Changing this parameter by ten percent in either direction does not appreciably change our conclusions.

${ }^{29}$ The report also describes annual costs for NOx in Table V-21(A). If we instead use these, we do not get quite the same discounted sum compared to subtracting out the sulfur costs from the EPA's reported total; using the vehicle cost number result in costs that are $\$ 2.3$ billion lower. To be conservative, we use the higher of the two total NOx cost numbers.

${ }^{30}$ These PM credits are the result of reducing non-NOx PM via increases in engine efficiency.
} 
that regulatory stringency will be a function of industry concentration. Similar to the electricity industry, the gasoline refining industry is much less concentrated than the automobile industry. Furthermore, given the inelastic nature of gasoline demand, much of the desulfurization costs likely fell onto consumers. Both of these industry features suggest that regulators will face less resistance when setting regulations on the refining market. This, too, represents an inefficiency; one that we do not attempt to quantify.

By separating the automobile manufacturer and desulfurization costs, we are able to isolate the costs incurred by automobile manufacturers and compare them to the costs incurred by electricity generators. For this reason, our preferred estimates of the costs associated with NOx abatement from the automobile sector is $\$ 896 /$ ton.

The RIA gives us one point on the total/average cost curve, but to calculate the level of inefficiencies across the two sectors requires a marginal abatement cost schedule for passenger vehicles. The RIA, states that "in the case of our standards, both the emission reductions and the fuel cost as a function of sulfur content are nearly linear, though the vehicle costs do contain some nonlinearity" (page VI-3). If we assume that the nonlinearity in the vehicle costs is minimal, this implies that total costs are linear in NOx abatement levels, and that marginal costs are constant and equal to the average cost number reported in Table 5. Insofar as the marginal cost curve is upward sloping, we will tend to overstate the inefficiencies present. Section 6 presents additional evidence to help assess the accuracy of the constant marginal cost assumption.

\subsection{Efficiency gains from equalizing marginal abatement costs}

With our estimates of the marginal abatement costs for the two industries in hand, we can now make comparisons across programs. More specifically, we estimate the costs of failing to equalize marginal costs across source types. These costs are best viewed graphically. Figure 5 is a stylized representation of our calculations. The width of the horizontal axis is the total discounted level of abatement from both sources (22.1 million tons), with abatement from point sources measured from left to right and abatement from mobile sources measured from right to left.

Our calculations imply that the existing regulations correspond to point A; the marginal abatement costs of point sources exceed those of mobile sources. We can calculate the potential efficiency gains by calculating the area of the triangle E. We do this using our alternative methods for accounting for sulfur and particulate matter costs when calculating the marginal abatement cost for mobile sources. These results are reported Table 5 . 
Regardless of how we credit for sulfur and PM, we find that we are over-regulating power plants. At the high end for the MAC for mobile sources of $\$ 1320 /$ ton, we estimate potential efficiency gains of $\$ 600$ million. Again for the reasons discussed above, this likely represents a lower bound on the potential efficiency gains. Our preferred estimate represents a modified Tier 2 policy focusing only on emissions control equipment. Under this scenario the MAC for mobile sources is $\$ 896 /$ ton yielding potential efficiency gain of $\$ 1.7$ billion. To put this number in perspective, the total compliance costs associated with point sources is $\$ 6.1$ billion, while the total compliance costs for mobile sources, absent desulfurization, is $\$ 13.75$ billion. An inefficiency of $\$ 1.7$ billion represents roughly nine percent of the total compliance costs. Accounting for the inefficiency across all three industries (electricity, refining and automobile) would yield even larger estimates.

\section{Additional Evidence on Marginal Abatement Costs}

In this section we present additional evidence on the accuracy of the cost estimates that we use.

\subsection{Power plants}

One potential check on the engineering estimates reflected in the aggregate marginal abatement cost curve for power plants is to compare the prices that have emerged in the market for permits under the NBP to the prices that are predicted by the engineering estimates we use. Specifically, if one considers the level of emissions reductions required under the NOx Budget Program, the price corresponding to this level of emissions reductions on our marginal abatement cost curve is $\$ 1920$ per ton. By comparison, over the period 2004-2008, permits in the NBP traded at an average price of $\$ 2080$ per ton. ${ }^{31}$

While these numbers are quite close, several caveats are in order. For one, previous work suggests that firms did not choose the least cost compliance options as suggested by the MAC curve that we use (Fowlie, 2008). On the other hand, there is anecdotal evidence to suggest the engineering cost estimates reflected in our marginal abatement cost curve might overstate realized costs.

\footnotetext{
${ }^{31}$ Permit price data are available from Evolution Markets LLC.
} 


\subsection{Vehicles}

We consider several benchmarks for the vehicle costs. First, as discussed in Section 2.2, the Tier 2 program was the most recent in a series of regulations aimed at reducing NOx emissions from passenger vehicles. The Tier 1 program, also part of the Clean Air Act Amendments, promulgated standards ranging from 0.60 grams/mile to 1.53 grams/mile depending on the vehicle weight (compare this to the Tier 2 requirement that fleets achieve an average emissions rate of 0.07 grams $/ \mathrm{mile}$ ). The Tier 1 standards became effective in 1991. At the end of the 1990s, the National Low Emissions Vehicle program represented a voluntary agreement between the EPA and the automobile manufacturers to reduce emissions ahead of Tier 2 by designing cars that achieved the California Low Emissions Vehicle standards. Under the program, vehicles were required to achieve emissions rates of 0.2 grams/mile by 2001 .

If the technology for reducing NOx has been roughly constant over the 1990s, cost estimates from these programs can provide several points along the MAC for NOx from vehicles. ${ }^{32}$ Essentially, each program brought about incremental reductions in NOx. If the costs of the later programs were much higher than the earlier programs, this could suggest a steep positively sloped MAC. In fact, engineering estimates from these two programs suggest that the steps were associated with roughly the same cost per ton reduced, and if anything were higher than the costs associated with Tier $2 .{ }^{33}$

While this pattern is consistent with a gently sloped or even constant marginal abatement curve up to the level of reductions achieved by Tier 2, it does not provide any insight on the costs of requiring reductions beyond Tier 2. Further, if the costs of the NLEV program truly are higher than the costs of Tier 2, the assumption of constant technology seems dubious, which calls into question the ability of the earlier programs to say anything about the incremental costs at Tier 2 . To get a sense for the costs of achieving reductions beyond those in Tier 2, we looked for evidence of steps that could have been taken but were not at the time that the Tier 2 regulations were adopted.

Our read of the relevant engineering literature suggests that available technology could have yielded reductions beyond those mandated by Tier 2. For instance, MECA (2003) describes several important ways in which NOx can be reduced using the conventional three-way catalytic converter

\footnotetext{
${ }^{32}$ The three-way catalytic converter has been the primary NOx control technology used in U.S. light-duty vehicles since the 1980s (MECA 2003).

${ }^{33}$ The regulatory impact analysis for Tier 1 reports cost effectiveness estimates of $\$ 2000-2750 /$ ton. The RIA for the NLEV cites a \$/ton figure drawn from a report done in 1994 analyzing the costs of extending California's LEV plan to the states in the ozone transport region. That report cites a figure of $\$ 3065 /$ ton, higher than the costs for either Tier 1 or Tier 2, although the report notes in words that technologies that the 1994 report expected to be required proved to be unnecessary (US EPA 1997 http://www.epa.gov/otaq/regs/ld-hwy/lev-nlev/sfrm-ria.pdf).
} 
technologies: placing the catalytic converter closer to the exhaust ports ("close-coupled" converters), denser substrates-the material which holds the catalyst, changing the process by which the catalyst is applied to the substrate and the specific mix of catalytic materials. They go on to describe tests done to several vehicles which demonstrate that using existing technologies, the vehicles could achieve up to 80 percent lower emissions than those required under Tier 2 (see MECA 2003, Figure 13). This is at least suggestive that requiring greater emissions reductions from cars than was required under Tier 2 would not have involved dramatically different technologies, so it is unlikely that the MAC beyond the Tier 2 reduction levels is steeply sloped.

The second indication that technologies were available to get additional reductions comes from the fact that different vehicles have achieved very different emissions rates. Under Tier 2, manufacturers were allowed to do fleet averaging. Specifically, each manufacturers' fleet had to achieve an average emissions level of 0.07 grams/mile, but individual vehicles could be tested up to a level of 0.14 grams/mile. ${ }^{34}$ We have obtained data on the dispersion in the emissions rates by vehicle in 2007, the first model year for which the full Tier 2 regulations were effective for the smaller trucks and cars. Even if all of the vehicles were using the exact same pollution control strategy, they would likely achieve different grams-per-mile emissions rates because of the variations in vehicle fuel efficiency. To address that, we have converted the grams per mile emissions to grams per gallon using information on vehicles' fuel efficiencies. The average ratio of emissions rates at manufacturers' 10th and 90th percentile vehicle was above 10 (see Figure 6). Although we do not have sufficient information to ascribe a particular cost to improving the efficiency of the vehicles on the right-hand side of Figure 6, the fact that the technology existed to reduce some vehicles' emissions to such low levels relative to other vehicles again suggests that the MAC is likely to be relatively flat for reductions beyond the Tier 2 levels.

\section{Relative Benefits from NOx Emissions Reductions}

Throughout the preceding analysis, we have assumed that the benefits per ton of NOx emissions reduction are equal across cars and power plants. In this section, we evaluate the plausibility of this assumption. A comprehensive comparison of damages per unit of NOx emitted from point versus mobile sources must account for a variety of factors including the location of the sources, the nature of chemical processes that form particulates and ambient ozone, and the population densities in affected areas. We present results from the regulatory impact analyses that were conducted prior

\footnotetext{
${ }^{34}$ This maximum does not become binding for the large trucks and sport-utility vehicles until 2009. (See Federal Register Vol. 65, No. 28, pp. 6855-6856, 6858, 6866.).
} 
to the promulgation of both rules. We also review the scientific evidence that has emerged since these rules were introduced. The section begins with a discussion of damages from exposure to particulates. We then consider ozone related damages.

\subsection{Avoided damages from exposure to particulates}

Particulate-related damages from NOx emissions can vary significantly across NOx emissions sources due to differences in chemical reaction rates, transport patterns, and exposure rates. The EPA carried out comprehensive impact assessments for both Tier 2 and the NOx emissions trading program (U.S. EPA, 1999a; U.S. EPA 1999b). In both assessments, the EPA used a national-scale sourcereceptor matrix based on the Climatological Regional Dispersion Model (CRDM) to evaluate the effects of the proposed regulations on ambient particulate matter concentrations. ${ }^{35}$

Both impact assessments provide estimates of effects on particulate matter concentrations. Tier 2 was projected to reduce average PM2.5 concentrations by 1.8 percent relative to a 2030 basecase. When weighted by population, the average reductions increases 2 percent (suggesting that a slightly larger proportion of reductions occur in more densely populated areas). Projected reductions in PM2.5 concentrations under the NBP are significantly smaller: average reductions and population weighted average reductions are 0.04 percent.

Direct comparisons of these estimated emissions reductions are complicated by the fact that the two analyses were conducted independently and measure impacts relative to different base years, and the significant differences in the size and scope of the two programs. ${ }^{36}$ Comparisons of the ratio of population weighted average reductions to unweighted reductions across programs are instructive. These rations are both close to one, suggesting that benefits are similarly distributed across densely populated and sparsely populated areas in both programs.

A recent case study offers a more direct "apples to apples" comparison of relative marginal damages across source types. Wolff (2000) analyzes formation and dispersion of nitrate particles for a random sample of coal-fired power plants and stretches of interstate highway across the United States. The study estimates the mass of secondary particulate matter inhaled per unit of emitted NOx and concludes that these estimated intake fractions are not statistically significantly

\footnotetext{
${ }^{35}$ Relative to more sophisticated and resource-intensive three-dimensional modeling approaches, the CRDM and its associated source-receptor matrix do not fully account for all the complex chemical interactions that take place in the atmosphere in the secondary formation of PM. In the RIA for Tier 2, analyses were also carried out using a Regional Particulate Model.

${ }^{36} \mathrm{NOx}$ reductions mandated under Tier 2 are more than three times as large as those mandated under the NBP. Tier 2 is also larger in scope; PM reductions were achieved directly (via new PM standards) and indirectly (via reductions in both $\mathrm{NOx}$ and $\mathrm{SO}_{2}$ ). Under the $\mathrm{NBP}$, all $\mathrm{PM}$ reductions are due to reductions in NOx precursors.
} 
different across the two source types. In sum, the findings of this study are consistent with our assumption that NOx emissions from vehicles regulated under Tier 2 cause similar damages, in terms of particulate-related damages per unit of NOx reduced, to emissions from large point sources regulated under the NBP.

\subsection{Avoided damages from ground-level ozone exposure}

Estimating the effects of NOx emissions reductions on ozone formation and exposure is more complicated. Ozone is formed by photochemical reactions involving two classes of precursors: volatile organic compounds (VOCs) and nitrogen oxides. An important feature of ozone chemistry is the complex and highly nonlinear relationship between precursor concentrations, temperature, and ozone production. ${ }^{37}$ Whereas ozone formation increases with NOx emissions in NOx sensitive photochemical regimes, the rate of ozone formation can decrease with increased NOx emissions when the ratio of NOx to VOCs is high. ${ }^{38}$

There are several reasons why the average ozone-related damages per unit of NOx emissions might differ across vehicles regulated under Tier 2 and coal-fired power plants regulated under the NOx Budget Program. First, the chemical processes that form ozone in the atmosphere are nonlinear, which means that any change in emissions will not be accompanied by a proportional change in amount of ozone. Mobile sources co-emit both ozone-precursors, resulting in immediate ozone production and higher ozone yields (Ryerson et al., 2003b). Coal-fired power plants emit highly concentrated NOx but almost no VOCs. Near the power plant stack, NOx concentrations are so high that ozone is actually removed from the plume. As the plume dilutes, NOX mixes with any VOCs available at the plume edge and ozone is produced. Production continues until the NOx is consumed or the sun goes down. Measurements taken in aircraft transects of emissions plumes and vehicular exhaust document substantial differences in the rate and magnituede of ozone production associated with NOx emissions from mobile and point sources. Recent studies find that ozone production efficiency (i.e., the net production of O3 per unit of NOx emitted) are significantly higher in vehicular exhaust versus power plant plumes (Luria et al., 1999; Ryerson et al., 2003; Sillman, 2007). Thus, with all other factors determining relative damages held constant, these documented differences in ozone production efficiency would imply that benefits per unit of NOx

\footnotetext{
${ }^{37}$ Other factors affecting ozone production efficiency include water vapor concentrations, vertical mixing rates, and other meteorological factors

${ }^{38}$ The term "NOx disbenefits" refers to the ozone increases that can result from NOx emission reductions in VOCconstrained areas. In areas dominated by NOx, ozone catalysts are removed via the production of nitric acid, which slows ozone formation. Because NOx is generally depleted more rapidly than VOC, this effect is usually short-lived, with NOx ultimately forming ozone further downwind.
} 
emissions reduction might be significantly higher under Tier 2 versus the NBP.

Differences in the spatial and temporal distribution of NOx emitted by NBP point sources and Tier 2 mobile sources are also important. ${ }^{39}$ With respect to the temporal dimension, all of the NOx emissions reductions achieved under the NBP occur during "ozone season," whereas NOx emissions reductions from Tier 2 occur year round. Because the photochemical reaction that forms ozone requires sunlight and heat, NOx emissions occurring in colder months are unlikely to contribute to ozone problems. Vehicular NOx emissions occur disproportionately in densely populated areas. Because mobile source NOx emissions occur where people are, and ozone formation from vehicular NOx emissions occurs very close to the source, ozone intake fractions are likely to be high for mobile sources. In contrast, coal plants tend to be located far from urban centers and ozone formed in power plant plumes can be deposited far from the source. Some of this ozone will be deposited over bodies of water or sparsley populated areas, implying that ozone intake fractions are likely to be lower, on average, for point sources.

In addition to reviewing the scientific literature relevant to a comparison of impacts of point versus mobile sources of NOx emissions, we also used the Air Pollution Emissions Experiments and Policy (APEEP) model to estimate the average monetary value of reduced particulate matter and ozone formation resulting from incremental reductions in NOx emissions at coal-fired plants regulated under the NBP and vehicles regulated under Tier 2, respectively (Muller and Mendelsohn, 2006). ${ }^{40}$ Because the APEEP model uses a reduced form approximation of ozone photochemistry (versus photochemical air quality simulations), estimates of the effects of small changes in NOx emissions on ozone formation at different locations should be interpreted with some caution. ${ }^{41}$ When this model is used to estimate marginal damages from NOx emissions, the average estimated damages at NBP sources is very similar to the average of county ground-level damage estimates

\footnotetext{
${ }^{39}$ Whereas the coal plants regulated under the NBP are all located in Eastern states (primarily in rural areas), Tier 2 sources are distributed across all states, except California, Alaska and Hawaii.

${ }^{40}$ We use the APEEP model to estimate the effects of incremental changes in NOx emissions at regulated sources on the formation and transport of nitrates. In each simulation, other components of the model are held fixed so that the resulting difference can be interpreted as the damage (measured in dollars) per ton of NOx emissions at the selected source. All damages are measured relative to those associated with observed 2002 emissions. Damages include adverse effects on human health, reduced yields of agricultural crops and timber, reductions in visibility, enhanced depreciation of man-made materials, and damages due to lost recreation services.

${ }^{41}$ The APEEP model uses a linear regression model to estimate ozone concentrations as a function of ambient concentrations of precursors (i.e., NOx, VOCs, and CO), ambient air temperature, and geography variables. Because precursor concentrations are highly correlated, it is difficult to obtain a precise estimate of the isolated effect of a change in NOx emissions on ozone concentrations, or to simulate the conditions in power plant plumes versus auto exhaust. Moreover, the model does not include interactions between the precursors, potentially missing some important dimensions of the ozone formation process, such as the presence of NOx disbenefits.
} 
(weighted by vehicle miles travelled). ${ }^{42}$ The APEEP model can be used to generate point estimates, but not standard errors, which makes it impossible to conduct formal hypothesis testing.

In sum, the state of scientific evidence on how ozone-related damages from NOx emissions compare across source types is far from conclusive. The evidence certainly does not contradict our simplifying assumption that these marginal damages per ton of NOx reduced do not differ significantly across source types, and, if anything, there is evidence suggesting that ozone damages are higher from passenger vehicles.

\section{Other NOx Programs}

The bulk of our analysis focuses on comparing the costs of reducing NOx from passenger vehicles to the costs of reducing NOx from power plants. As depicted in Figure 1, these two sources account for less than half of the man-made NOx in the U.S.: passenger, or light-duty, vehicles emitted 18 percent of U.S. NOx in 2002, just before the Tier 2 standards came into effect, and electric utilities emitted 23 percent. The remaining emissions come from non-highway mobile sources, such as farm and construction equipment (20 percent), heavy-duty highway vehicles (19 percent) and industrial processes and sources (19 percent). Trends in emissions from these five categories suggest different time paths of emissions reductions. As shown in Figure 7, there have been dramatic improvements in the emissions of NOx from light-duty vehicles, while the emissions from the other sources have remained more constant. ${ }^{43}$

Recently, both heavy-duty highway and non-highway mobile sources have been subject to more stringent regulations, and the regulatory impact analyses provide engineering estimates of the relative costs of reducing NOx from these sources. There have been two sets of regulations aimed at heavy-duty highway vehicles. Regulations promulgated in 1997 and effective in 2004 required a number of minor changes to heavy-duty diesel and gasoline trucks, such as injection timing retard.

\footnotetext{
${ }^{42}$ Mean damages per ton of NOx are $\$ 247$ (standard deviation $\$ 850$ ) for vehicles. To estimate marginal benefits associated with emissions reductions at coal-fired power plants, we estimate the value associated with incrementally changes in NOx emissions at each plant. Mean damages are $\$ 277$ (standard deviation \$578). These estimates are quite low, in part refelecting the fact that the model uses lower estimates of the value of a statistical life than the EPA. Another reason is that the APEEP model predicts very large NOx disbenefits in urban areas. Whereas the analysis conducted for the regulatory impact assessments indicated that only a few locations in the center of large metropolitan areas might experience a slight ozone increase on some days as a consequence of NOx reductions (64 FR 26018), the APEEP model predicts significant NOx disbenefits in 25 percent of counties and at roughly 25 percent of NBP facilities.

${ }^{43}$ Kahn and Schwartz (2008) also provide evidence suggesting that NOx emissions from vehicles has declined dramatically.
} 
These changes were estimated to be extremely cost effective at a range of roughly $\$ 100-\$ 300$ per ton including markups. The next set of regulations, enacted in 2000 to be effective in 2007, required new technology, such as "clean gas induction," 44 selective catalytic reduction, and the development of new catalysts, and entailed costs per ton that were approximately an order of magnitude higher than the first set of regulations. ${ }^{45}$ These cost estimates are also very close to the cost estimates for vehicles under Tier 2. Engineers with whom we have spoken contend that achieving reductions beyond what was required by the 2007 regulations would have involved implementing new and as yet untested technologies and could involve much higher costs. In light of this, and in light of the difference between the 2004 and 2007 regulations, it seems likely that the marginal cost of abatement is steeply sloped for trucks. Hence, equalizing marginal abatement costs between trucks and power plants would not obviously lead to efficiency gains as large as the ones we describe for passenger vehicles.

Non-road diesel vehicles and engines are another story. ${ }^{46}$ NOx standards for non-road diesel engines have historically been extremely lax. In 1998, standards were adopted that reduced NOx and particulate matter by as much as two-thirds for some engines. The EPA calculated the cost of achieving these reductions for a wide array of engine sizes, ranging from 25 horsepower to over 1000 horsepower. For many of these engines, the legislation simply required using technologies already in use for on-road vehicles. Using assumptions similar to those for the Tier 2 analysis (their assumed markup is 29 percent), the EPA calculated the average cost of abatement for six engines sizes. The average cost of abatement varies across the engine size, but for the largest size (also the largest polluters), the costs ranged from $\$ 10-110$ per ton; the average abatement cost for the smaller sizes are typically below $\$ 600$ per ton.

There are two reasons to believe these are actually upper bounds. For one, these calculations do not account for the reduction in particulate matter, which were considerable. Second, many of the compliance strategies improve the operating efficiency of the engines. Factoring in the reduced operating costs suggest negative average abatement costs for many engines. While one can view

\footnotetext{
${ }^{44}$ Clean gas induction recylces cleaned exhaust gas into the intake. By burning the exhaust twice NOx is reduced.

${ }^{45}$ The 2007 regulations gave manufacturers the option of fleet averaging. Specifically, either the entire fleet must meet a standard of $1.1 \mathrm{~g} / \mathrm{bhp}$, or half of the fleet can meet a standard of $2.0 \mathrm{~g} / \mathrm{bhp}$ and the other half $0.2 \mathrm{~g} / \mathrm{bhp}$. The EPA also required manufacturers to determine the technologies that they planned on using for the 2007 standards by the end of 2003, suggesting a significant amount of R\&D was required by manufacturers.

${ }^{46}$ The EPA distinguishes on-road diesel engines from non-road by the following four factors: (1) the engine is used in a piece of motive equipment that propels itself in addition to performing an auxiliary function (such as a bulldozer grading a construction site); (2) the engine is used in a piece of equipment that is intended to be propelled as it performs its function (such as a lawnmower); (3) the engine is used in a piece of equipment that is stationary but portable, such as a generator or compressor; or (4) the engine is used in a piece of motive equipment that propels itself, but is primarily used for off-road functions.
} 
the negative abatement costs with some skepticism, the improved efficiency certainly reduces the social abatement costs.

\section{Conclusions and Discussion}

Large scale, market-based air pollution regulations such as the Acid Rain Program and the NOx Budget Program have successfully taken advantage of significant gains from trade among large industrial sources of pollution. Here, we present evidence to suggest that there is also significant potential for efficiency improvements from coordinating abatement activity across mobile and point source pollution types. We estimate that the total compliance costs incurred are almost 10 percent (or nearly $\$ 2$ billion) higher than the minimum costs required to achieve the combined reductions mandated by these two programs. Although the cost inefficiency is slightly lower in percentage terms than estimates for intra-sector gains from the adoption of the market-based policies, because the combined costs of programs across multiple sectors will be larger than the cost of any single program, the efficiency gains in dollar terms are likely to be higher.

There are a number of reasons to believe our estimates represent a lower bound of the productive inefficiencies present in regulating NOx. First, there is strong evidence to suggest that other mobile sources, such as on- and off-road diesel, have lower marginal abatement costs than passenger vehicles. Second, while we have noted that the desulfurization program imposed on refiners was an inefficient way to reduce NOx (even after crediting for the reduced sulfur from the program), we do not estimate the gains from scaling it back. Finally, we note that our results are based on comparing a market-based program for power plants to a command-and-control standard for motor vehicles. This makes our estimates of the marginal cost of abating NOx emissions from vehicles an upper bound on the true marginal cost if a more market-based approach were adopted. For instance, if regulators were able to pass a "NOx tax," the market might uncover a number of less expensive abatement strategies, such as driving less or retiring old vehicles.

These findings are particularly relevant to the ongoing debate over how to design policies to address climate change. There is tremendous pressure on regulators to find ways to keep the economic costs of achieving proposed greenhouse gas reduction targets to a minimum. In theory, an economy wide tax or cap-and-trade program should ensure that marginal abatement costs are equated across all sources. Several of the proposed pieces of climate change legislation would have point and mobile sources of greenhouse gas emissions regulated under the same market-based regulatory program. ${ }^{47}$ Others have argued that the transportation sector, which accounts for 27

\footnotetext{
${ }^{47}$ Four bills currently under consideration in the U.S. Senate are set mandatory caps on economy-wide greenhouse
} 
percent of total U.S. greenhouse gas emissions, should be regulated separately from large point sources (Farrell and Sperling, 2007). This paper illustrates the potential for inefficiency when sectors and source types are regulated separately.

gas emissions and either mandate or recommend a market-based cap-and-trade permit system. 


\section{References}

[1] Aldy, Joseph, and William Pizer. 2008. "Issues in Designing U.S. Climate Change Policy." Resources for the Future Discussion Paper DP 08-20.

[2] Borenstein, Severin, James Bushnell, and Frank Wolak. 2002. "Measuring Market Inefficiencies in California's Wholesale Electricity Industry." American Economic Review, 92 (5): 1376-1405.

[3] Brunekreef, B. and S. T. Holgate (2002). "Air pollution and health." Lancet 360: 1233-1242.

[4] Chay, Kenneth, and Michael Greenstone. 2003. "The Impact of Air Pollution on Infant Mortality: Evidence from Geographic Variation in Pollution Shocks Induced by a Recession." Quarterly Journal of Economics, 118(3):1121-1167.

[5] Electric Policy Research Institute.1999a. Application of Methodology for Identification of Least Cost NOx Control Combinations. Palo Alto, CA: EPRI.

[6] Electric Policy Research Institute.1999b. UMBRELLA: Software for Assessing NOx Control Technology Combinations, Version 1.0. Palo Alto, CA: EPRI.

[7] Farrell, Alexander E., and Daniel Sperling. 2007. "A Low-Carbon Fuel Standard for California, Part 2: Policy Analysis." University of California, Davis mimeo.

[8] Fowlie, Meredith. 2009. "Emissions Trading, Electricity Industry Restructuring, and Investment in Pollution Abatement." Forthcoming in American Economic Review..

[9] Gryparis, Alexandros, Bertil Forsberg, Klea Katsouyanni, Antonis Analitis, et al. 2004. "Acute Effects of Ozone on Mortality from the 'Air Pollution and Health: A European Approach' Project." American Journal of Respiratory and Critical Care Medicine, 170(10):1080-1087.

[10] Himes, Richard. 2004. Electric Power Research Institute. Telephone conversation, July 12.

[11] Joskow, Paul, and Edward Kahn. 2002. "A Quantitative Analysis of Pricing Behavior in California's Wholesale Electricity Market During Summer 2000." The Energy Journal, 23(4):1-35.

[12] Kahn, Matthew, and Joel Schwartz. 2008. "Air Pollution Progress Despite Sprawl: The "Greening" of the Vehicle Fleet." Journal of Urban Economics, 63(3): 775-787.

[13] Keohane, Nathaniel. 2005. "Environmental Policy and the Choice of Abatement Technique: Evidence from Coal-Fired Power Plants." Yale University mimeo. 
[14] Lippman, Morton, and Richard B. Schlessinger. 2000. "Toxicological Bases for the Setting of Health-Related Air Pollution Standards." Annual Review of Public Health, 21: 309-333.

[15] Luria, Menachem, Ralph J. Valente, Roger L. Tanner, Noor V. Gillani, et al.1999. "The Evolution of Photochemical Smog in a Power Plant Plume." Atmospheric Environment, 33(18): 3023-3036.

[16] Manufacturers of Emission Controls Association. 2003. Tier 2/LEV II Emission Control Technologies For Light-Duty Gasoline Vehicles. Washington. DC: MESA.

[17] Muller, Nicholas, and Robert Mendelsohn. 2008. "Efficient Pollution Regulation: Getting the Prices Right." Forthcoming in American Economic Review.

[18] Muller, Nicholas, and Robert Mendelsohn. 2007. "Measuring the damages of air pollution in the United States." Journal of Environmental Economics and Management. 54(1):1-14.

[19] Muller, Nicholas, and Robert Mendelsohn. 2006. "The Air Pollution Emission Experiments and Policy Analysis Model (APEEP). Technical Appendix.” December.

[20] Musatti, Daniel. 2004. U.S. Environmental Protection Agency. Email correpondence. June 7.

[21] Natural Gas Week. 2004. "Extra Credits Will Keep Fuel Switching Down." April 23, 2004.

[22] Olley, Steven, and Ariel Pakes. 1996. "The Dynamics of Productivity in the Telecommunications Equipment Industry." Econometrica. 64(6): 1263-1297.

[23] Ozone Transport Assessment Group. 1997. Executive Report.

[24] Pavcnik, Nina. 2002. "Trade Liberalization, Exit, and Productivity Improvements: Evidence from Chilean Plants." Review of Economic Studies. 69(1): 245-276.

[25] Ryerson, T.B., M. Trainer, J.S. Holloway, D.D. Parrish, L.G. Huey, D.T. Sueper, G.J. Frost, S.G. Donnelly, S. Schauffler. E.L. Atlas, W.C. Kuster, P.D. Goldan, G. Hubler, J.F. Meagher, F.C. Fehsenfeld. 2001. "Obervations of Ozone Formation in Power Plant Plumes and Implications for Ozone Control Strategies." Science, 292 (5517): 719-723.

[26] Ryerson, T.B., Trainer, M., Nicks, D.K., Neuman, A.J., Holloway, J.S., .Brock, C.A., Jakoubek, R.O., Parrish, D.D., Seuper, D.T., Frost, G.J., Kuster, W.C., Goldan, P.D., Dissly, R.W., Hubler, G., Angevine, W.M., Fehsenfeld, F.C., Donnelly, S.G., Schauffler, S., Atlas, E.L., Weinheimer, A.J., Flocke, F., Wert, B.P., Potter, W.T., Fried, A., Wiedinmyer, C. , 
Senff, C.J., Banta, R.M., Darby, L.S., Alvarez, R.J. 2003b. "Effect of petrochemical industrial emissions of reactive alkenes and NOx on tropospheric ozone formation in Houston, TX." Journal of Geophysical Research-Atmospheres,108(D8).

[27] Shadbegian, Ron, Wayne Gray, and Cynthia Morgan. 2006. "A Spatial Analysis of the Consequences of the $\mathrm{SO}_{2}$ Trading Program." Preliminary paper presented at Market Mechanisms and Incentives: Applications to Environmental Policy, EPA NCEE and NCER conference, Washington DC.

[28] Sillman, Sanford. 2003. "Tropospheric Ozone and Photochemical Smog," in B. Sherwood Lollar, ed., Treatise on Geochemistry, Vol. 9: Environmental Geochemistry, Ch. 11, Elsevier.

[29] Srivastava, Ravi. 2004. U.S. Environmental Protection Agency. Telephone conversation. June.

[30] Stavins, Robert. 1998. "What Can We Learn from the Grand Policy Experiment? Lessons from SO2 Allowance Trading." The Journal of Economic Perspectives, 12(3): 69-88.

[31] Stigler, George. 1971. "The Theory of Economic Regulation." Bell Journal of Economics, 2(Spring): 3-21.

[32] Subcommittee on National Economic Growth, Natural Resources and Regulatory Affairs. 1999. "Congressional letter to EPA on Tier II/Gasoline sulfur proposal." August 5.

[33] U.S. Environmental Protection Agency. 2005. Evaluating Ozone Control Programs in the Eastern United States: Focus on the NOx Budget Trading Program, 2004. Office of Air and Radiation, Office of Air Quality Planning and Standards, Washington DC, August.

[34] U.S. Environmental Protection Agency. 2003. Documentation Supplement for EPA Modeling Applications (V.2.1.6) Using the Integrated Planning Model. Office of Air and Radiation. Washington D.C. July.

[35] U.S. Environmental Protection Agency. 1999a. Regulatory Impact Analysis - Control of Air Pollution from New Motor Vehicles: Tier 2 Motor Vehicle Emissions Standards and Gasoline Sulfur Control Requirements. Office of Air and Radiation. Washington D.C. December.

[36] U.S. Environmental Protection Agency. 1999b. Regulatory Impact Analysis for the final Section 126 Petitionn Rule. Office of Air and Radiation. Washington D.C. December.

[37] U.S. Environmental Protection Agency. 1998a. Regulatory Impact Analysis for the NOx SIP Call. Office of Air and Radiation, Washington DC, October. 
[38] U.S. Environmental Protection Agency. 1998b. Feasibility of Installing NOx Control Technologies by May 2003. Office of Atmospheric Programs, Acid Rain Division, Research Triangle Park, NC, September.

[39] U.S. Environmental Protection Agency. 1997. Regulatory Impact Analysis for the Particulate Matter and Ozone National Ambient Air Quality Standards and the Proposed Regional Haze Rule. Office of Air Quality Planning and Standards, Research Triangle Park, NC. July.

[40] Wolff, Scott. 2000. "Evaluation of Fine Particulate Exposures, Health Risks, and Control Options." PhD diss. Harvard School of Public Health.

[41] Wolfram, Catherine. 1999. "Measuring Duopoly Power in the British Electricity Spot Market." American Economic Review, 89(4): 805-826.

[42] World Health Organization. 2003. "Health Aspects of Air Pollution with Particulate Matter, Ozone and Nitrogen Dioxide." WHO Working Group, Bonn, Germany. January 13-15. 


\section{A Data Appendix (Not for Publication)}

\section{Unit-level compliance strategy choices}

1. EPA Electronic Data Reporting for the Acid Rain Program/subpart H. The EPA collects hourly data from over 900 U.S. power plants who are required by law to install and operate Continuous Emissions Monitoring Systems (CEMS). All units that are affected by the Acid Rain Program, the NOx Budget Trading Program and/or the NOx SIP Call are subject to the monitor-

ing and reporting provisions of Subpart H. Units must report what type of NOx controls they are operating, installation dates and hours of operation.

2. Energy Information Administration (EIA). Facilities must also report information about NOx controls annually to the EIA.

3. Institute for Clean Air Companies: Collects information about pollution control retrofits from press releases, annual reports, and other sources.

4. MJ Bradley \& Associates: Maintains a comprehensive database containing unit-specific information regarding pollution control equipment.

\section{Data required to estimate control costs at the unit level}

1. U.S. EPA National Electric Energy System (NEEDS): (see above). Includes over 20 unit level variables, including capacity, heat rate, online year, firing and bottom types. Data are annual; most recent data are 2000 .

2. EPA Electronic Data Reporting for the Acid Rain Program/subpart H: The EPA collects hourly data from over 900 U.S. power plants who are required by law to install and operate continuous emissions monitoring systems (CEMS). All the plants in my sample are subject to the monitoring and reporting provisions of subpart H. This database contains thousands of variables, most of which are measured hourly at the unit level. Data are available with approximately a six month lag.

3. U.S. EPA Emissions and Generation Integrated Database (EGRID): EGRID consolidates available plant level data for all U.S. power plants that are obliged to report data to the U.S. government. EGRID reports data on an annual level for hundreds of variables at the boiler, plant, company, parent company and state level. The most recent data are 2000.

4. Energy Information Administration (EIA) Form 767 : Power plants(non-nuclear) larger than 10MW are required to submit form EIA-767 annually. The forms collect data on plant opera- 
tions and equipment design (including boilers, generators, cooling systems, flue gas desulfurizations, flue gas particulate collectors, and stacks). Most recent data are 2002.

5. Energy Information Administration (EIA) Form 860: Power plants(non-nuclear) larger than 10MW are required to submit form EIA-767 annually. The forms collect generator-specific information such as initial date of commercial operation, generating capacity, ownership and energy sources.

6. Platts BaseCase: A comprehensive database covering supply, electric demand, transmission interfaces, and Platts fuel price forecasts, as well as unit-level hourly data. Compiled from EIA, FERC, NERC, CEMS, RUS, utility reports, manufacturers' publications, and Platts sources.

7. Raftelis Financial Consultants Water and Wastewater Rate Survey.

8. Bureau of Labor Statistics: Regional estimates of boilermaker and construction wages.

9. Personal Correspondence: Representatives from the major coal-fired boiler manufacturers (Alstom Engineering, Babcock Power, Foster Wheeler, Riley Power Inc.) provided valuable information about the technical specifications of the boilers in the sample De-NOx Technologies LLC provided data on reagent and reagent transportation costs. Other technical assistance was provided by Cichanowicz Consulting Engineers LLP.

\section{Permit Price/Transaction Data}

1. Evolution Markets LLC

Estimates of anticipated post-retrofit NOx emissions rates (conditional on boiler characteristics) constructed using the following sources:

1. Biewald, B., J. Cavicchi, T. Woolf and D. Allen. 2000. "Use of Selective Catalytic Reduction for control of NOx Emissions from Power Plants in the U.S." Synapse Energy Economics Inc.

2. Cichanowicz, J.E. 2004. "Why are SCR costs still rising?". Air Quality Control, 148( 3): 32.

3. Electric Policy Research Institute. 1999. "Application of Methodology for Identification of Least Cost NOx Control Combinations."

4. Electric Policy Research Institute. 1999. UMBRELLA: "Software for Assessing NOx Control Technology Combinations, Version 1.0."

5. Farzan, H. G.J. Maringo, D.W. Johnson, D.K. Wong . 1999. "B\&W's Advances on Cyclone NOx Control via Fuel and Air Staging Technologies", EPRI_DOE_EPA Combined Utility Air Pollutant Control Symposium, Atlanta GA. 
6. Staudt, J. "Technologies and Cost Effectiveness of Post-Combustion NOx Controls." Andover Technology Partners, http://www.netl.doe.gov/publications/proceedings/99/99scr-sncr/staudt.pdf.

7. Steitz, T.H., R.W. Cole. 1999. "Field Experience in Over 30,000 MW of Wall Fired Low NOx Installations." Foster Wheeler Energy Corporation.

8. U.S. Department of Energy. 2002. "Full-Scale Demonstration of Low-NOx Cell Burner Retrofit." http://www.netl.doe.gov/cctc/summaries/clbrn/cellburnerdemo.html.

9. U.S. Environmental Protection Agency. 2002. Documentation Supplement for EPA Modeling Applications (V.2.1) Using the Integrated Planning Model. Office of Air and Radiation. Washington D.C.

10. U.S. Environmental Protection Agency. 1999. Regulatory Impact Analysis for the Final Section 126 Petition Rule, Office of Air and Radiation, Washington DC.

11. U.S. Environmental Protection Agency. 1998. Regulatory Impact Analysis for the NOx SIP Call, Office of Air and Radiation, Washington DC.

12. U.S. Environmental Protection Agency. 1998, Feasibility of Installing NOx Control Technologies by May 2003, Office of Atmospheric Programs, Acid Rain Division, Research Triangle Park, NC.

13. U.S. Environmental Protection Agency. 1998. Regulatory Impact Analysis for the NOx SIP Call, FIP and Section 128 Petitions, Office of Air Quality Planning and Standards, Office of Atmospheric Programs, Washington D.C.

14. U.S. Environmental Protection Agency. 1998. Analyzing Electric Power Generation under the CAAA. Office of Air and Radiation. Washington D.C. 
Table A-1: Generating Unit Characteristics

\begin{tabular}{ll}
\hline \hline Variable & \\
\hline \# Units & 632 \\
\# Facilities & 221 \\
Capacity [MW] & 275 \\
& $(261)$ \\
Age [years in 2000] & 35 \\
& $(13)$ \\
Pre-retrofit Emissions & 0.50 \\
[lbs NOx/kWh] & $(0.22)$
\end{tabular}

Notes: Standard deviations are in parentheses. The unit of analysis is a generating unit or boiler. 


\section{B Tables and Figures}

\section{B.1 Tables}

Table 1: Costs and Emissions Reductions for a Representative Unit

\begin{tabular}{|c|c|c|c|}
\hline$j$ & $\begin{array}{l}c_{j} \\
(\$ 000 ’ s)\end{array}$ & $\begin{array}{l}R_{j} \\
\text { (tons } \mathrm{NOx} \text { ) }\end{array}$ & $\begin{array}{l}M A C_{j} \\
(\$ / \text { ton })\end{array}$ \\
\hline $\mathbf{0}$ & $\mathbf{0}$ & 0 & - \\
\hline 1 & 6,996 & 5,361 & - \\
\hline 2 & 6,078 & 6,177 & - \\
\hline 3 & 4,864 & 6,730 & 723 \\
\hline 4 & 10,102 & 8,100 & - \\
\hline 5 & 12,854 & 9,470 & - \\
\hline 6 & 11,885 & 10,865 & 1,698 \\
\hline 7 & 40,956 & 19,238 & 3,472 \\
\hline 8 & 51,533 & 19,333 & 112,116 \\
\hline \multicolumn{4}{|c|}{ Source: EPRI's UMBRELLA software. } \\
\hline
\end{tabular}

Table 2: Variable Costs Associated with Tier 2 (\$ per vehicle)

\begin{tabular}{lccccc}
\hline \hline & LDV & LDT 1 & LDT 2 & LDT 3 & LDT 4/MDPV \\
\hline 4 Cylinder & 24.99 & 13.16 & 8.16 & N/A & N/A \\
6 Cylinder & 65.16 & 91.46 & 90.98 & 238.86 & N/A \\
8 Cylinder & 75.42 & N/A & 70.97 & 171.99 & 171.99 \\
Larger 8/10 Cylinder & N/A & N/A & N/A & N/A & 291.54 \\
Sales Weighted & 44.69 & 39.87 & 84.27 & 178.74 & 187.53 \\
\hline Notes: LDV = Light Duty Vehicles, LDT = Light Duty Trucks, \\
MDPV = Medium Duty Personal Vehicle (i.e., vehicles in excess of 8,500 lbs.) \\
Source: EPA (1999a) Table V-2.
\end{tabular}


Table 3: Variable, Fixed, Markup and Learning Costs (\$ per vehicle)

\begin{tabular}{lccccc}
\hline \hline & LDV & LDT 1 & LDT 2 & LDT 3 & LDT 4/MDPV \\
\hline First and Second Year & 82.43 & 73.80 & 129.54 & 248.92 & 267.57 \\
3rd Year: Learning begins & 75.22 & 68.50 & 119.90 & 222.60 & 233.52 \\
6th Year: Fixed Costs Expire & 53.19 & 49.03 & 100.64 & 202.99 & 212.34 \\
\hline \multicolumn{5}{l}{ Source: Authors calculations using data from EPA (1999a). } \\
\hline
\end{tabular}

Table 4: Emissions and Savings due to Tier 2 Vehicles in the 47 Affected States

\begin{tabular}{cccccc}
\hline \hline & & \multicolumn{5}{c}{ Contribution by } & Vehicle Class & \\
Year & Light Duty Emissions (tons) & LDV & LDT1/2 & LDT 3/4 & Savings (tons) \\
\hline 2000 & $3,548,883$ & $52.1 \%$ & $30.0 \%$ & $17.9 \%$ & - \\
2004 & $3,612,395$ & $43.5 \%$ & $37.1 \%$ & $19.4 \%$ & 326,556 \\
2007 & $3,681,990$ & $37.3 \%$ & $41.0 \%$ & $21.7 \%$ & 959,512 \\
2010 & $3,817,070$ & $33.0 \%$ & $42.7 \%$ & $24.3 \%$ & $1,554,442$ \\
2015 & $4,116,074$ & $28.6 \%$ & $44.3 \%$ & $27.1 \%$ & $2,527,309$ \\
2020 & $4,502,761$ & $26.9 \%$ & $45.2 \%$ & $27.8 \%$ & $3,205,571$ \\
2030 & $5,323,860$ & $27.1 \%$ & $45.5 \%$ & $27.4 \%$ & $4,049,687$ \\
\hline
\end{tabular}

Source: EPA (1999a) Table III.A-1.

Table 5: Average Costs Associated with Tier 2 and Potential Efficiency Gains

\begin{tabular}{lcc}
\hline \hline & $\begin{array}{c}\text { Average/Marginal Cost } \\
\text { Method for dealing with other emissions }\end{array}$ & \\
\hline (\$) ton of & NOx+NMHC) & Inefficiency \\
\hline Creredited MAC & 2040 & - \\
Credited MAC* & 1320 & $\$ 600$ million \\
Credited MAC*, w/ a zero markup & 1164 & $\$ 900$ million \\
Separated MAC & 1108 & $\$ 1.1$ billion \\
Separated MAC, w/ a zero markup & 896 & \\
\hline$*$ Assumes $\$ 10,000 /$ ton for PM (a total credit of $\$ 3.5$ billion) & & \\
Sulfur $($ a total credit of $\$ 13.8$ billion) & & \\
\hline
\end{tabular}




\section{B.2 Figures}

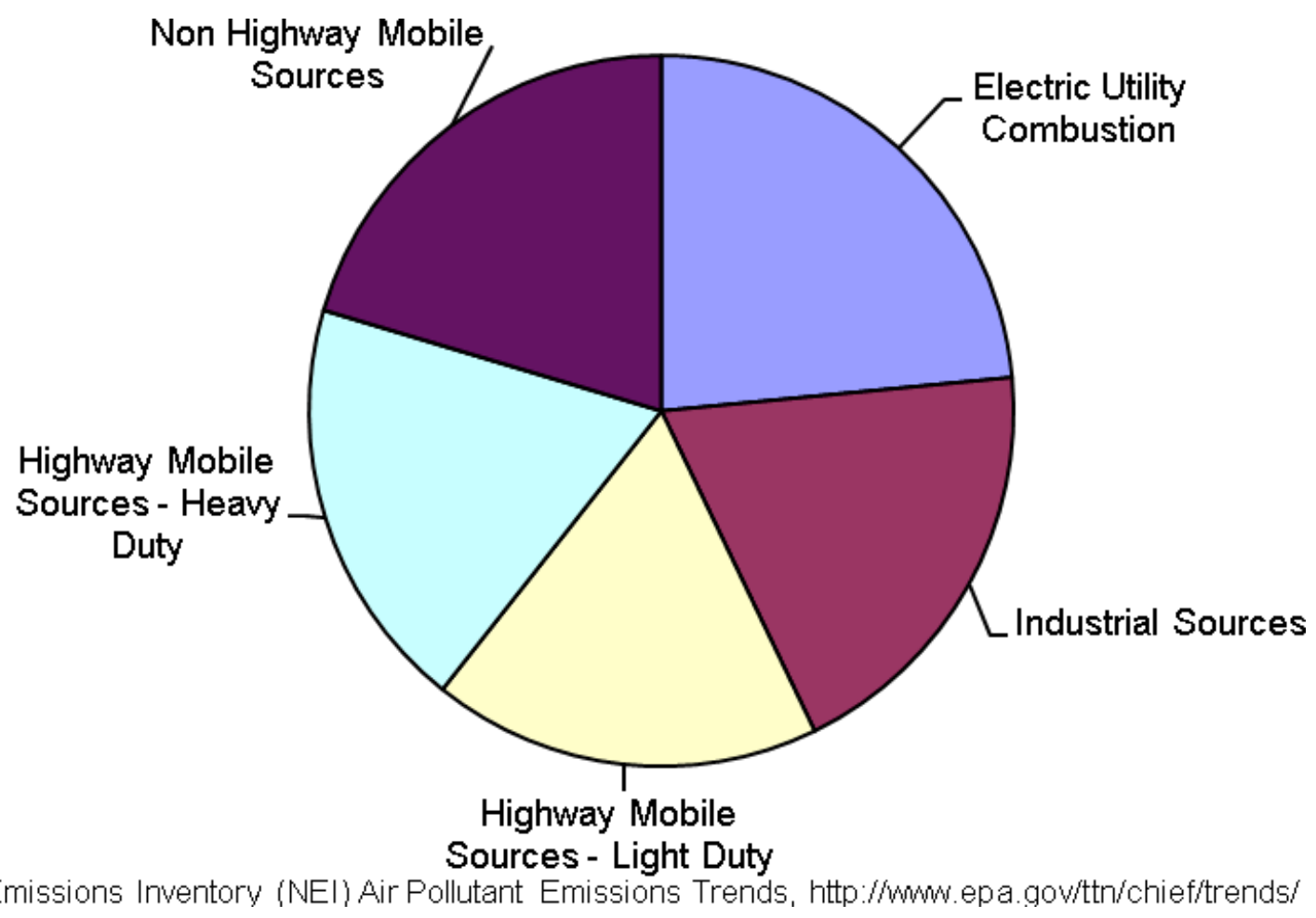

Source: National Emissions Inventory (NEl) Air Pollutant Emissions Trends, http://wmw.epa.gov/ttn/chief/trends/

Figure 1: NOx Emissions by Source, 2002 


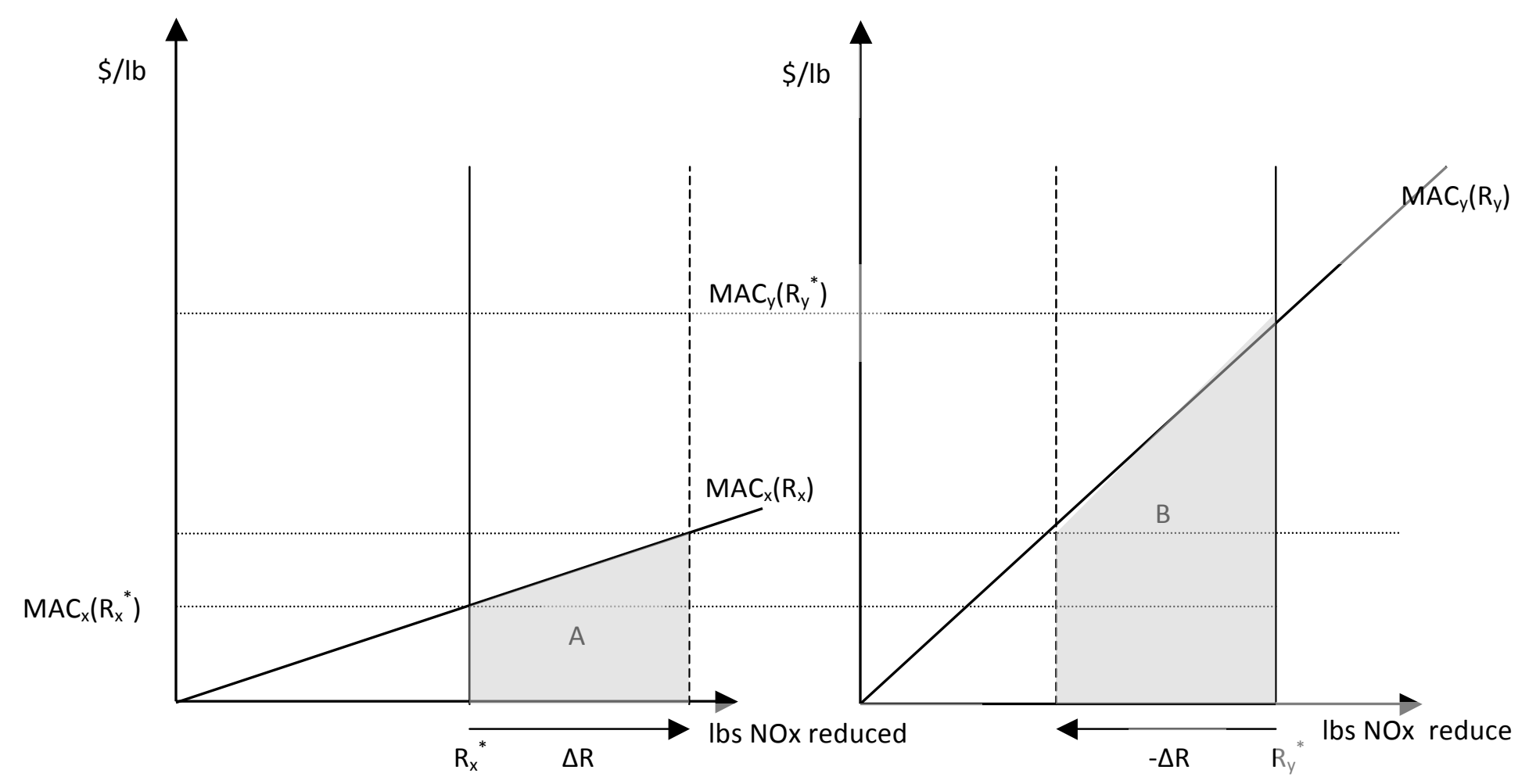




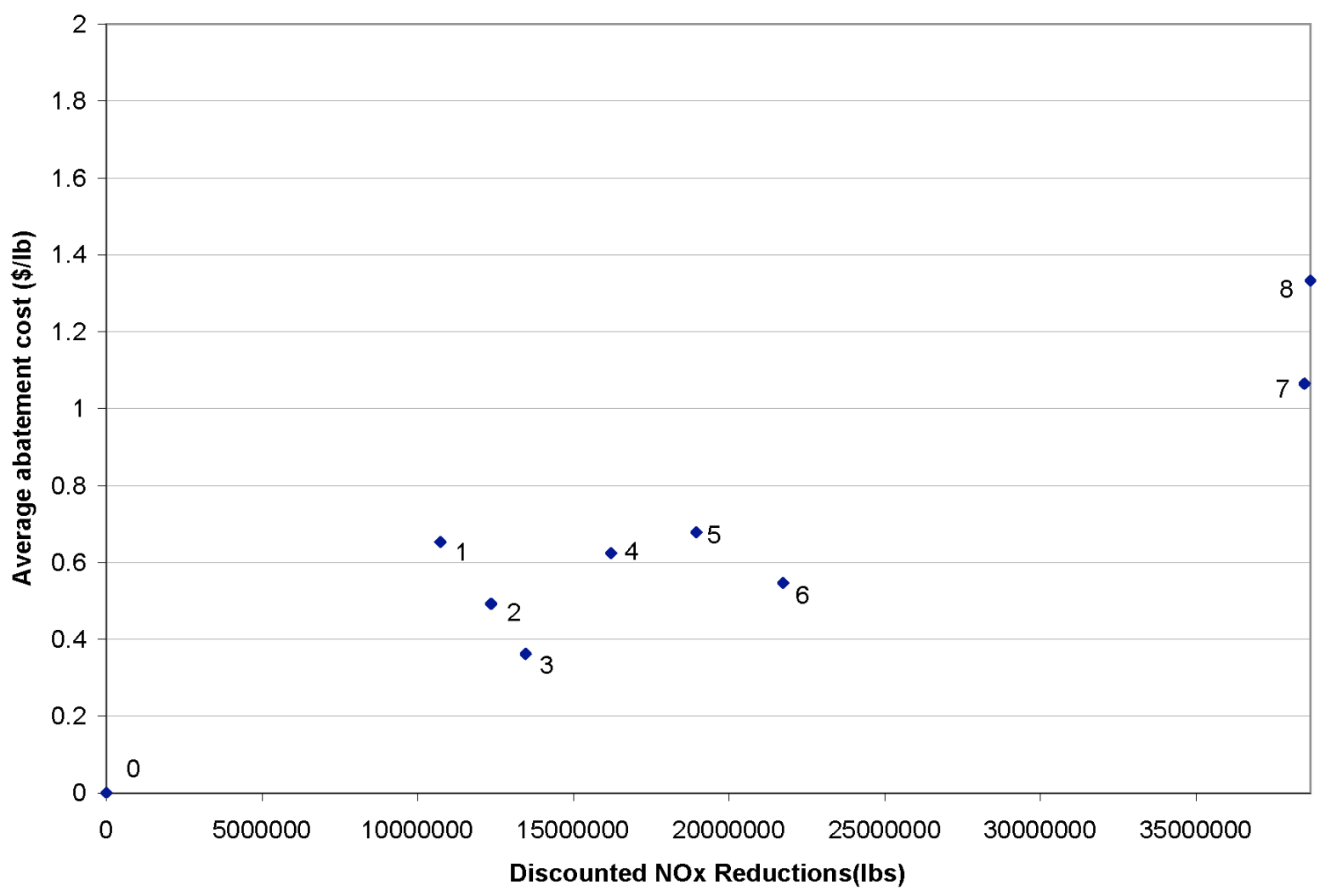

Figure 3: NOx Control Costs for a Representative Unit 


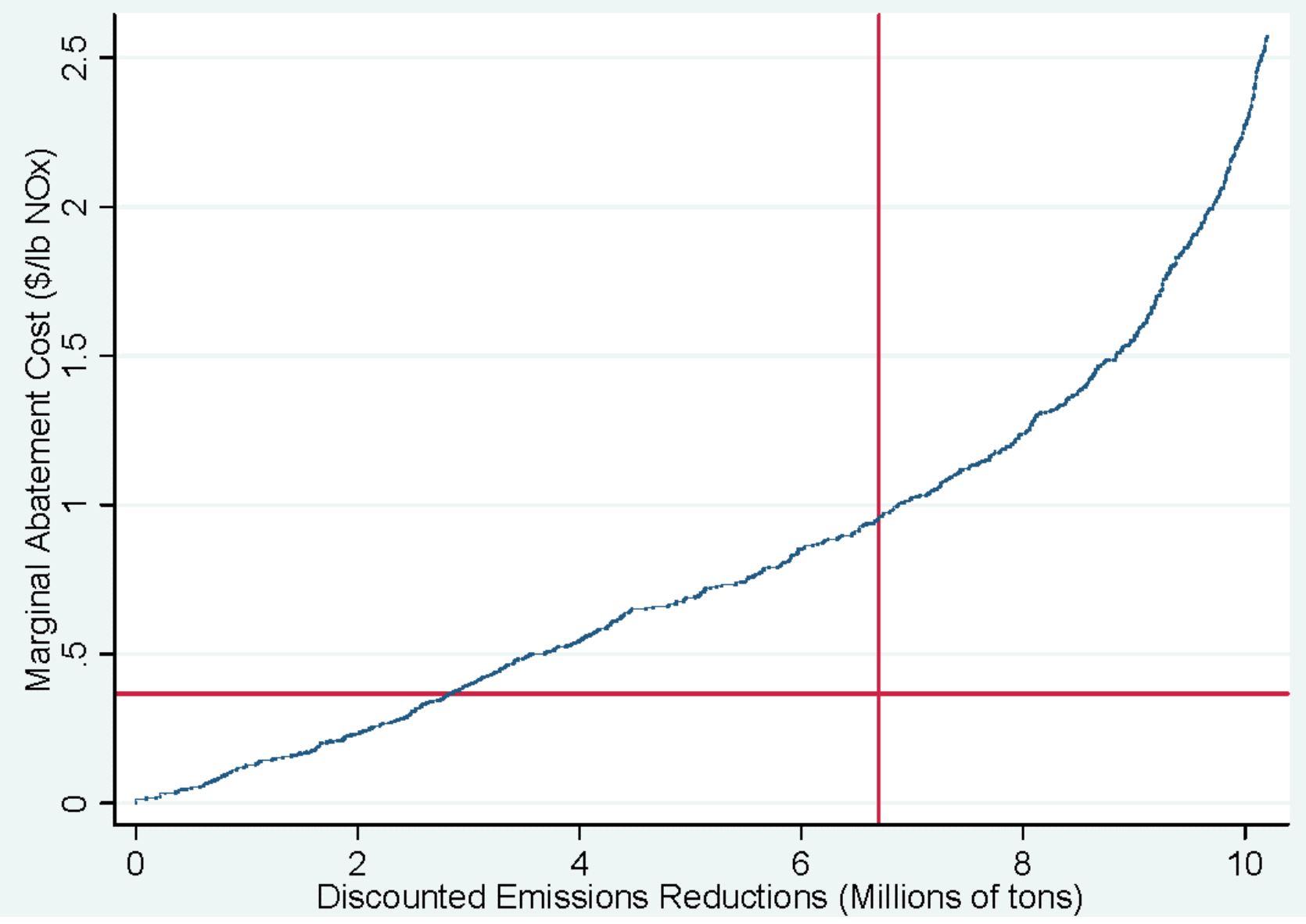

Figure 4: Marginal Abatement Cost Curve for Coal-Fired Electricity Generators in the NOx Budget Program 


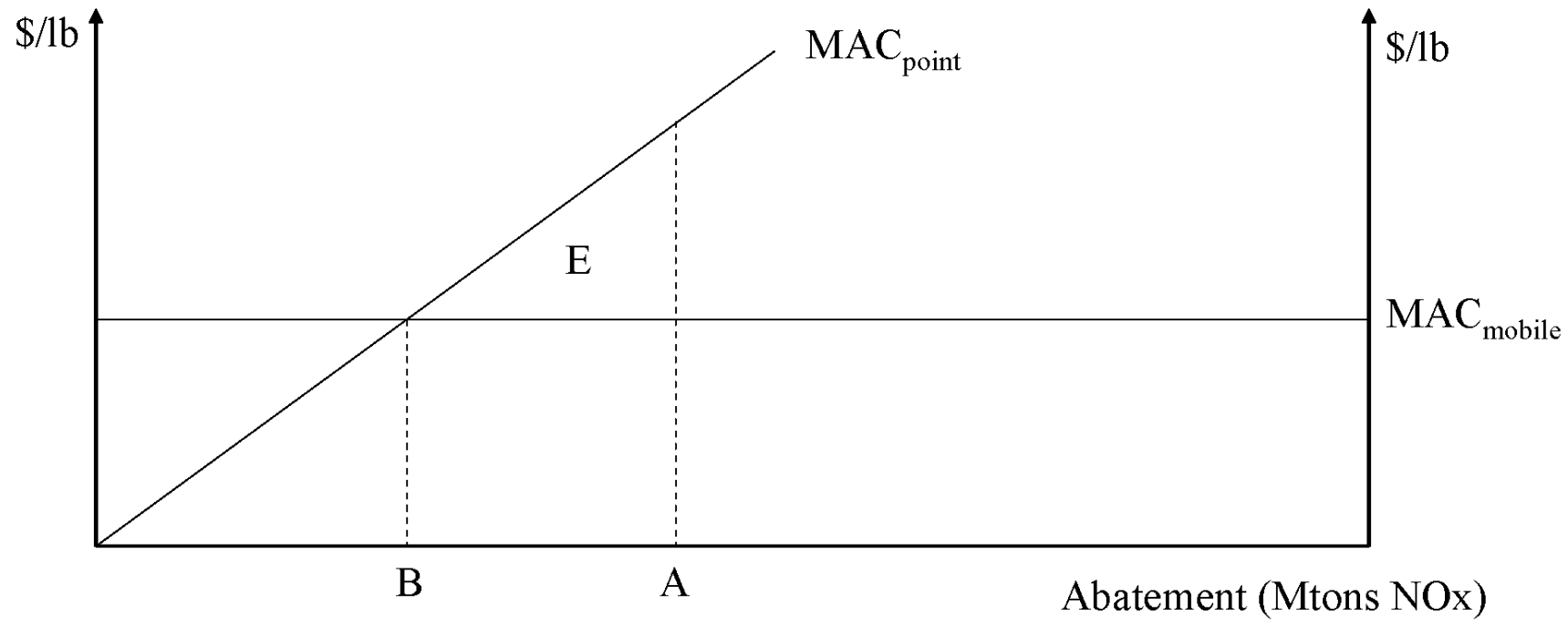

Figure 5: Measuring Efficiency Gains 


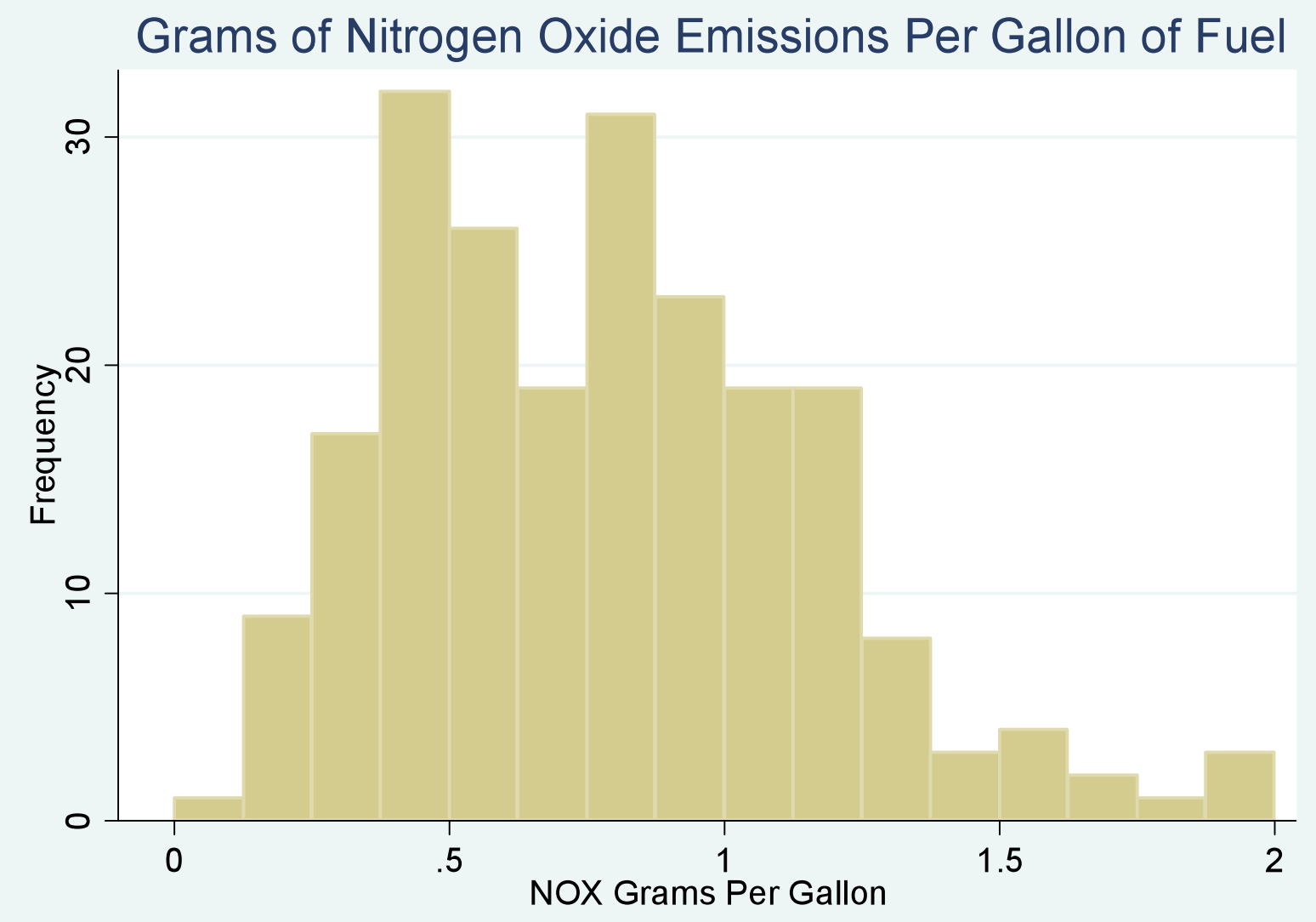

Figure 6: Distribution of Grams of NOx Emissions per Gallon 


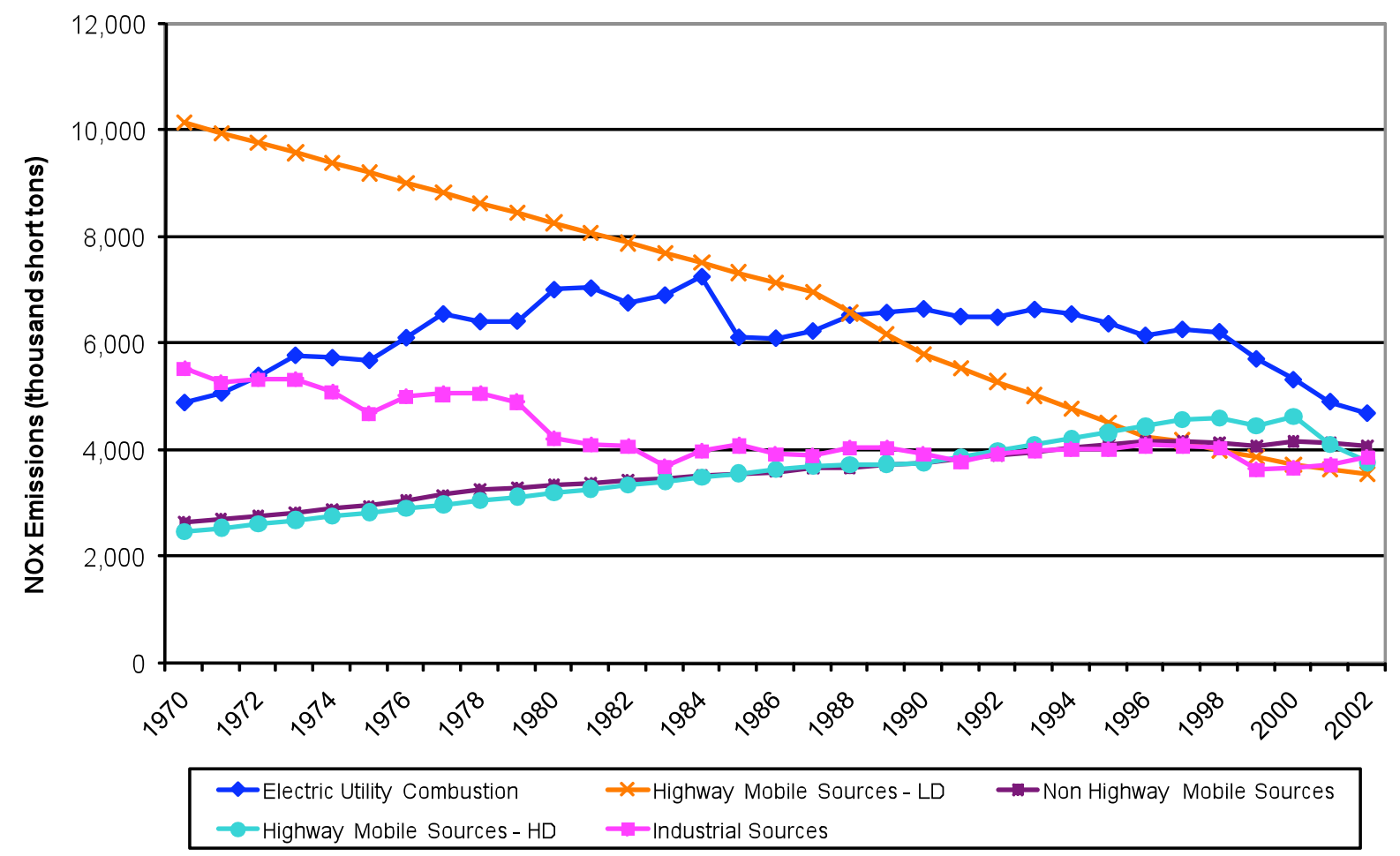

Figure 7: Trends in NOx Emissions by Source: 1970-2002 